\title{
Seismic Vulnerability of URM Structures based on a Discrete Macro-Element Modeling (DMEM) Approach
}

César Chácara ${ }^{1,2}$, Francesco Cannizzaro ${ }^{3}$, Bartolomeo Pantò ${ }^{3}$, Ivo Caliò ${ }^{3}$, Paulo B. Lourenço ${ }^{2}$

${ }^{1}$ Pontificia Universidad Católica del Perú, San Miguel Lima 32, Lima, Perú. Phone: +51 16262000,E-mail: c.chacara@pucp.pe

2 ISISE, University of Minho, Department of Civil Engineering, Azurém, 4800-058 Guimarães, Portugal. Phone: +351 253510 200, fax: +351 253510 217, E-mail: pbl@civil.uminho.pt

${ }^{3}$ University of Catania, Department of Civil Engineering and Architecture, 95125 Catania, Italy. Phone: +39 095738 2275, fax: +39095 738 2249, E-mail:

francesco.cannizzaro@dica.unict.it, bpanto@dica.unict.it, icalio@dica.unict.it 


\section{Abstract}

The assessment of the seismic vulnerability of unreinforced masonry (URM) structures based on numerical modeling constitutes a difficult task due to their complex behavior, especially in the nonlinear dynamic field, and the lack of suitable, low-demanding, computational tools. In the last decades, practical statistical tools for the derivation of fragility curves has been successfully proposed mainly with reference to framed structures. This approach has been adopted also for the seismic vulnerability assessment of masonry buildings focusing on the inplane collapse mechanisms by means of equivalent frame models. Nevertheless, the lack of computationally effective tools which involve the interaction between in-plane and out-of-plane mechanisms makes the definition of fragility curve an arduous task when it comes to existing masonry structures without box behavior.

In this paper, a practical and thorough methodology for the assessment of the seismic vulnerability of URM buildings by means of analytical fragility curves is presented. This methodology presents some innovative features such as the definition of the limit states (LSs) and their corresponding capacity based on multi-directional pushover analyses, as well as the application of nonlinear dynamic analyses, performed using a discrete macro-element modelling approach capable of simulating the main in-plane and out-of-plane responses of URM structures with a reduced computational burden. The present investigation focuses on the application of this methodology for assessing the seismic vulnerability of a brick masonry structure characterized by a strong out-of-plane failure mechanism. After a fitting process, the fragility curves were compared to the ones obtained using expert-based approaches.

Keywords: Brick masonry structure, Multi-directional pushover analysis, Nonlinear dynamic analysis, Displacement capacity, Analytical fragility curves, HiStrA software. 


\section{Introduction}

Masonry buildings constitute the most scattered low-rise structural typology in the world, mainly because of its economic affordability and constructive ease. In addition to residential buildings, the vast majority of heritage constructions, usually made of brick, stone or adobe, also belong to this structural typology. These structures are often located in areas with high seismic activity, and most of them were built without following specific seismic design standards. It is well-known that, besides being an important cause of human losses, earthquakes constitute a major threat involving the stability of this typology of structures. Therefore, the seismic vulnerability assessment of this structural typology is a relevant topic within the different fields concerning decision making, risk prediction and management of seismic hazard. Nevertheless, masonry structures present a response difficult to predict due to the high uncertainty associated with variables such as their mechanical, geometrical or structural parameters, or load conditions to which they are subjected to. Considering the high uncertainty of this type of buildings, deterministic approaches are less suitable for assessing the seismic vulnerability of URM structures. In this sense, stochasticprobabilistic methodologies are desirable to better understand the seismic vulnerability assessment of this type of structures [1].

Seismic vulnerability assessment is often performed using practical statistical tools such as fragility functions which allow the estimation of the probability of reaching or exceeding a limit state (LS) due to a given Intensity Measure (IM) [2]. Fragility functions can be defined following different approaches, namely expert-based, analytical, empirical and hybrid formulations [3]. The definition of fragility functions by means of expert-based formulations involves a substantial and detailed assessment of an estimate of damage level provided by a team of experts [4]. Nevertheless, due to the diverse individual experiences of the experts, damage estimates with a high level of consensus may not be reached, making this type of formulation somehow limited. On the other hand, empirical-based fragility functions involve a statistical elaboration of data obtained from post-earthquake surveys. This type of formulation is based on a more realistic source of information (such as structural 
typologies, soil effects and site characteristics) allowing a more accurate assessment of the seismic vulnerability. Fragility functions derived from analytical formulations involve the development of structural models and the subsequent performing of numerical simulations. Even though this type of fragility functions may increase the reliability of the seismic vulnerability assessment by reducing the bias associated with expert-based formulations, its derivation still presents some important limitations. Sophisticated numerical tools require a significantly large computational burden and the extensive knowledge of input parameters. Furthermore, most simplified models currently used for the numerical simulations are not capable of providing a realistic prediction of the earthquake structural response since they neglect the interaction between in-plane and out-of-plane mechanisms.

Another important aspect that plays a fundamental role in the assessment of seismic vulnerability, based on nonlinear analyses, corresponds to the definition of appropriate IMs and LSs. Macroscale intensity measures as the Peak Ground Acceleration (PGA) constitute parameters commonly used for the derivation of fragility functions due to the simple physical meaning they provide [5]. Other parameters such as the peak ground velocity, the spectral acceleration or spectral displacement, the Arias and Housner intensities have been considered as IMs for seismic vulnerability assessment [6]. LSs are related to the response of a building, and they are commonly based on its structural performance. This performance is often related to interstory drifts formulations as specified in different codes or standards [7-11] or proposed by different authors [12-15]. The most common formulation for assessing the seismic vulnerability of masonry structures is based on the interstory drift capacity. As reported in the EC8-Part3 [9], the definition of this displacement-based formulation is associated with the type of mechanism governing the collapse of the structure. For instance, a lateral drift of $0.4 \%$ is proposed for a Significant Damage LS when the structure experiences a shear failure, and $0.8 \%\left(H_{0} / L\right)$ when the collapse is ruled by a flexural mechanism, being $H_{0}$ and $L$ the distance between the contra-flexure point and the point in which the flexural capacity is attained, and the in-plane length of the wall, respectively. It is worth to note that similar failure mechanism-based procedures have been adopted 
119 by additional standards such as Italian Code [11], FEMA 273 [7] and FEMA 306

120 [8]. A summary of the different interstory drift-based procedures and a detailed 121 comparison can be found in the work presented by Petry and Beyer [16]. On the other hand, a multiscale approach was proposed in $[17,18]$ for the definition of LSs. This approach involves the structure performance assessment at three different levels: i) local, ii) global, and iii) macro-element. The application of this approach is mainly suitable for multistory masonry buildings in which the global behavior is most influenced by the in-plane response of masonry walls. The assessment of buildings characterized by flexible diaphragms or by the absence of diaphragms requires additional criteria. In this regard, the authors have proposed the application of macro block models in order to assess the out-of-plane mechanisms of this type of buildings and its integration with the multiscale approach.

Very few studies are devoted to the assessment of the seismic vulnerability of unreinforced masonry buildings based on fragility functions [19]. Rota, et al. [5] investigated the seismic vulnerability of some typical Italian masonry structures using empirical fragility functions. The derivation of such functions was based on post-earthquake damage data relative to 91,934 buildings, classified into twentythree structural typologies, and the definition of five LSs in accordance with the European Macroseismic Scale [20]. The seismic vulnerability assessment required the formulation of Damage Probability Matrices for each structural typology and PGA interval. A similar investigation regarding Iranian buildings was carried out by Omidvar, et al. [21] in 2012.

The seismic vulnerability of masonry structures has also been investigated by means of analytical formulations and the use of simplified computational tools.

144 For instance, Park, et al. [22] investigated the seismic vulnerability of low-rise

145 URM buildings located in the central and southern regions of the US using 146 simplified numerical models. In this sense, the walls loaded in the in-plane direction were modeled as an arrangement of nonlinear links in series, whereas the walls loaded in the out-of-plane direction and horizontal diaphragms were simulated as single nonlinear links. Four LSs together with their corresponding 
interstory drift capacities were established in accordance with specifications provided by HAZUS [23].

Pasticier, et al. [24] investigated the seismic vulnerability of a typical twostory stone masonry building using an equivalent frame modeling approach, performed with the software SAP2000 [25], consistent with the three LSs defined in the EC8-Part3 [9]. The global behavior of the building was firstly investigated through static pushover analyses. Subsequently, a simplified model of the building's façade was subjected to Incremental Dynamic Analysis (IDA) based on fourteen earthquake ground motion records with different scaling factors. In such investigation, the uncertainty was focused on the PGA, which was also considered as IM.

Asteris [14] defined specific damage states for the evaluation of the seismic vulnerability of masonry structures. These states were used for the seismic assessment of a Greek historical monastery [26]. In such investigation, fragility curves were derived by means of $\mathrm{FE}$ numerical simulations. The seismic vulnerability also involved the use of different restoration mortars in order to determine the best alternative for strengthening purposes. The mortars were obtained by means of an inverse engineering procedure aiming at assuring their compatibility with the original constituent material [27]. Asteris, et al. [28] also investigated the seismic vulnerability of historical masonry structures located in Portugal, Cyprus and Greece. Numerical models of these masonry structures, based on the FE method, were used for the generation of fragility curves. In a more recent investigation, Asteris, et al. [1] presented a methodology for seismic vulnerability assessment which involves activities such as geometrical reconstruction, mechanical characterization, numerical modeling, definition of seismic actions and failure criteria, application of strengthening techniques, and derivation of fragility curves. The latter investigation also considered that the limit states were based on a damage-based approach. The methodology was applied to a set of masonry walls considering uncertainty related to tensile strength, percentage of openings, and peak ground acceleration.

The seismic vulnerability of an Italian typological three-story masonry building was assessed by Rota, et al. [19]. An equivalent frame computational 
model, implemented in the software TreMuri [29], was subjected to static and dynamic nonlinear analyses. The application of pushover analyses was based on an incremental lateral force proportional to the first vibration mode, whereas the time history analyses involved real ground motion records properly scaled to match the response spectrum.

Erberik [30] assessed the seismic vulnerability of Turkish masonry buildings through the application of static and dynamic nonlinear analyses using the software SAM [31]. The buildings were classified into different groups considering criteria such as the number of stories, material, length of walls and openings and regularity in plan. Two shear capacity-based LSs and PGA as IM, which ranged between $0.01 \mathrm{~g}$ and $0.80 \mathrm{~g}$, were established for the assessment of the seismic vulnerability of such structures. Additional investigation associated with masonry structures can be found in [32-34].

Most of the investigations conducted so far are based on simplified numerical models which do not allow to consider the interaction between in-plane and out-of-plane mechanisms. In addition, they mainly focused on the seismic response of URM structure due to the application of nonlinear static analysis, which neglects the degradation of stiffness and strength due to the unloading and reloading cycles. In this sense, the assessment of the seismic vulnerability of URM structures requires thorough methodologies based on the use of numerical strategies able to provide a more realistic earthquake response still maintaining a low computational burden. This paper aims at proposing a methodology for the seismic vulnerability assessment of an URM structure using a simplified computational tool capable of simulating the in-plane and out-of-plane mechanisms. The computational tool, named Discrete Macro-Element Modeling (DMEM) approach, is also characterized by a reduced number of degrees of freedom (DOFs) which allows the application of nonlinear dynamic analysis with a low computational demand. In addition, a multidirectional pushover analysis technique is used for the definition of the displacement capacity of the

211 URM structure. Based on the results of this investigation, it was possible to 212 demonstrate the applicability of this methodology for the assessment of the 213 seismic vulnerability of URM structures. 


\section{The Discrete Macro-Element Modeling (DMEM)} approach

An alternative modeling approach for assessing the in-plane response of masonry structures was initially introduced by Caliò, et al. [35] in which masonry structures were represented by means of two-dimensional panels. Each panel can be represented according to a mechanical scheme composed by a rigid hinged quadrilateral and two diagonal nonlinear links. As depicted in Figure 1a, the connection between two adjacent panels is ruled by a zero-thickness interface discretized with a number of nonlinear links placed in the direction orthogonal to its length and a single nonlinear link placed along its length.

This simplified modeling approach is capable of simulating the main inplane failure mechanisms of masonry structures which are governed by a different set of nonlinear links. The flexural mechanism, associated with the crushing of masonry in the compressive area and the rupture in the tensile area, is governed by the nonlinear links orthogonally distributed along the length of the interface element. The in-plane shear-sliding mechanism or slipping of masonry in the direction parallel to the mortar joints, which occurs for low values of cohesion or friction force, is simulated by means of the single sliding nonlinear link in the interface element. Finally, the in-plane shear-diagonal mechanism, related to the formation of diagonal cracking, as a consequence of low values of tensile strength, is ruled by the couple of diagonal nonlinear links at the panel. The kinematics of each panel is described by four Lagrangian parameters associated with the rigid body motion and the shear deformability of a masonry panel.

The plane mechanical scheme can be efficiently adopted for describing the global response of masonry buildings governed by the in-plane behavior of masonry walls assuming that the out-of-plane mechanics are prevented. In order to overcome this significant restriction, an upgrade of the plane element was carried out by Pantò, et al. [36]. The extension of the element to spatial behavior

242 has been obtained by introducing two-dimensional interface element characterized by new sets of nonlinear links allowing the simulation of out-ofplane mechanisms. The two-dimensional interface element is now discretized into 
mechanism of this type of structures. The out-of-plane sliding and the torsional responses of URM structures are simulated by two additional links which are

248 placed along the thickness of the interface element. As illustrated in Figure 1b,

249 the mechanical scheme of the upgraded model is now composed of four rigid plates connected by hinges and a single diagonal nonlinear link which governs the inplane shear-diagonal mechanism of URM structures. The kinematics associated with a single spatial panel is described by seven kinematic variables associated with the rigid body motion and the in-plane shear deformability of the corresponding masonry panel.

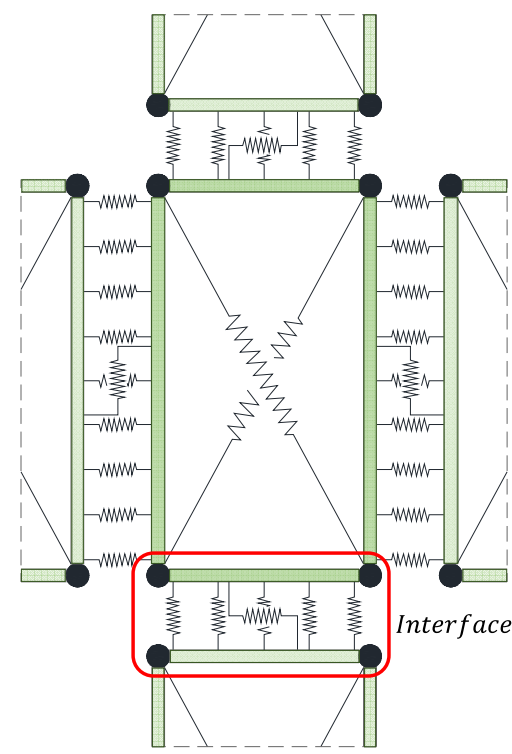

(a)

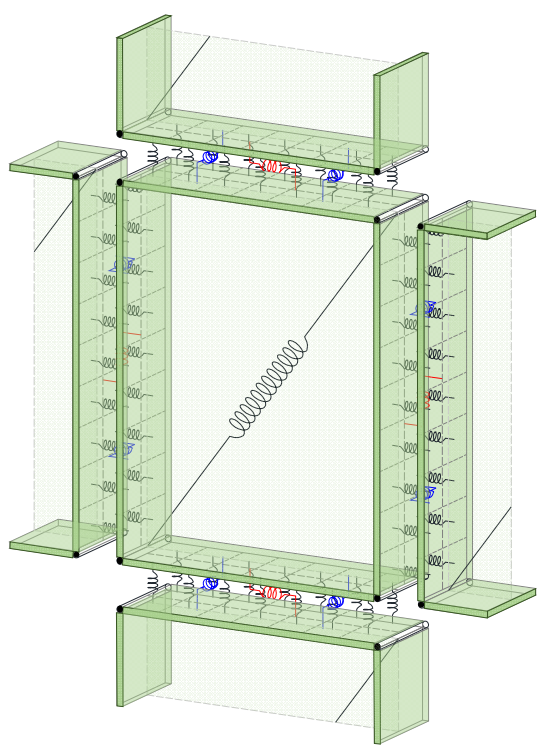

(b)

Figure 1. Discrete Macro-Element Modeling approach: (a) two- and (b) threedimensional mechanical configurations.

An accurate simulation of the combined interaction between in-plane and out-of-plane responses of URM structures requires adequate calibration

257 procedures for each set of nonlinear links. Different methodologies are followed for estimating the linear mechanical properties of the links at an interface level and the diagonal link placed on each panel. The calibration procedure associated with

260 the transversal and sliding links is based mainly on a fiber approach. Based on 261 this approach, each adjacent panel is divided into a compound of fibers in accordance with the discretization of the connecting interface element. Each fiber represents a strip of masonry in a given direction, and it is characterized by an 
influence area ( $A_{F}$ for the transversal links, and $A_{S}$ for the sliding link), and an equivalent length $l$. In the case of rectangular elements, the initial flexural stiffness $k_{F}$, related to the transversal links, is reported in equation (1) where $E$ represents the masonry Young's modulus. The initial stiffness $k_{S}$ associated with the sliding response, expressed in equation (2), is defined as a function of the shear modulus $G$ and a shear factor denoted as as whose value ranges between 0 and 1 [36]. This parameter describes the contribution of the in-plane sliding links and the diagonal link on the overall in-plane elastic shear stiffness of the DME model. If it presents a value equal to 1 , the in-plane sliding links are characterized

273 by a rigid behavior and the overall in-plane stiffness is given by the diagonal links.

274 The out-of-plane links contemporary govern the out-of-plane shear and torsion 275 stiffness of the masonry macro portion simulated by the DME model. The elastic stiffness of each link is evaluated according to an afference volume associated with half $A_{S}$ (Figure 2c) while its mutual distance $d$, given in equation (4), is estimated in order to reproduce the elastic torsional stiffness of the masonry portion $\left(k_{\phi}\right)$. The latter is evaluated according to equation (3) where $J_{\phi}$ is the torsional rigidity factor of the panel cross section.

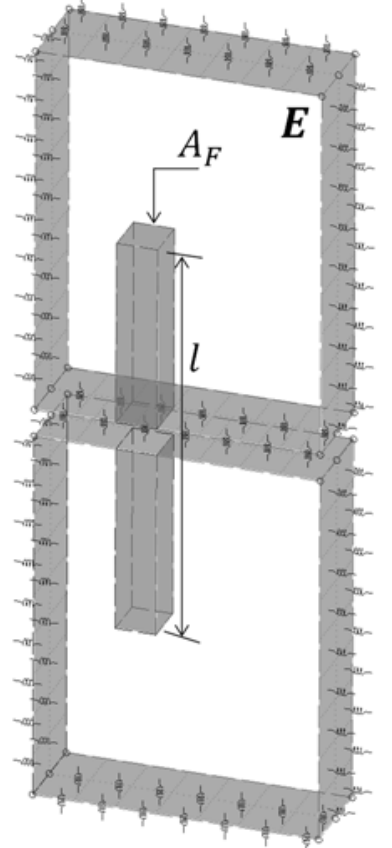

(a)

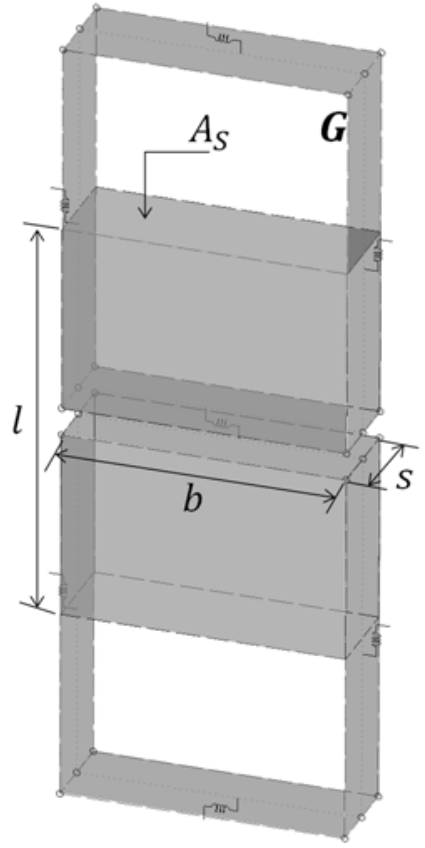

(b)

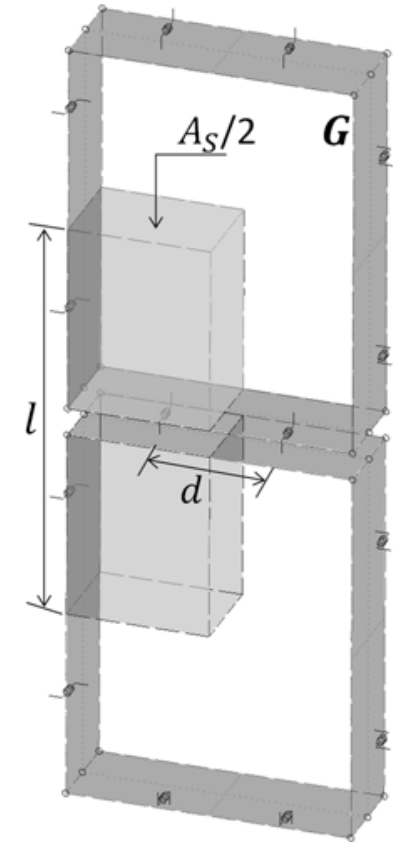

(c)

Figure 2. Fiber calibration procedure for: (a) transversal links, (b) in-plane and (c) out of plane sliding links. 


$$
\begin{aligned}
& k_{F}=\frac{2 E A_{F}}{l} \\
& k_{s}=\frac{G A_{s}}{l\left(1-\alpha_{s}\right)} \\
& k_{\phi}=\frac{G}{l} J_{\phi}=\frac{G}{l}\left\{b s^{3}\left[\frac{1}{3}-0,21 \frac{s}{b}\left(1-\frac{s^{4}}{12 b^{4}}\right)\right]\right\}= \\
& d=2 s \sqrt{\frac{1}{3}-0,21 \frac{s}{b}\left(1-\frac{s^{4}}{12 b^{4}}\right)}
\end{aligned}
$$

The nonlinear and cyclic behaviors of these links (transversal and sliding) are characterized by different constitutive models. The nonlinear response of the transversal links is described by exponential (tension) and parabolic (compression) constitutive laws. The cyclic behavior of these links corresponds to a hysteretic Takeda model [37]. Due to the frictional phenomenon of the sliding links, their nonlinear behavior is described by a Mohr-Coulomb yielding criterion, whereas the cyclic response of this set of links is associated with an elasto-plastic hysteretic model. The cyclic constitutive models for these typologies of nonlinear links, namely the transversal and sliding links, are illustrated in Figure 4 in which $F_{t}$ and $F_{c}$ are the tensile and compression strengths of transversal links (Figure 2a), whereas $F_{y}$ corresponds to the ultimate strength sliding links (Figure $2 \mathrm{~b}$ ).

The calibration procedure of the diagonal nonlinear link is conducted by enforcing an equivalence between a finite portion of masonry with pure shear deformability, as shown in Figure 3. Based on this equivalence, the shear diagonal stiffness $k_{D}$ is given as a function of the shear modulus $G$, the transversal area $A T$, the shear factor $a_{s}$, the height $h$, and the angle $\omega=\arctan (h / b)$ described between the diagonal link and the horizontal edge of the panel. The expression that describes the initial shear-diagonal stiffness is reported in equation (5).

$$
k_{D}=\frac{G A_{T}}{\alpha_{s} h \cos ^{2} \omega}
$$




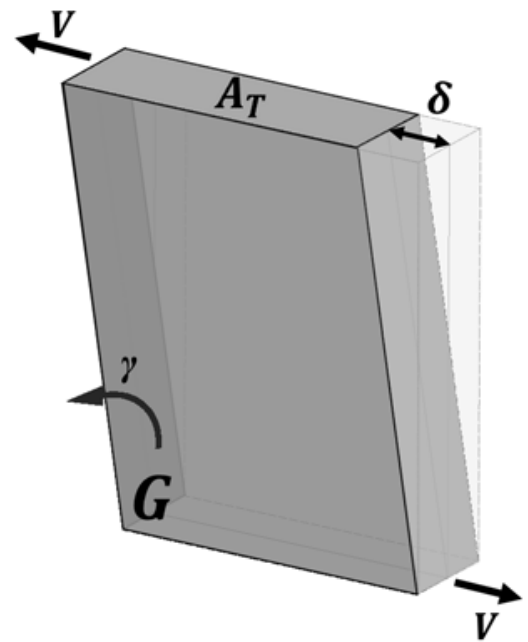

(a)

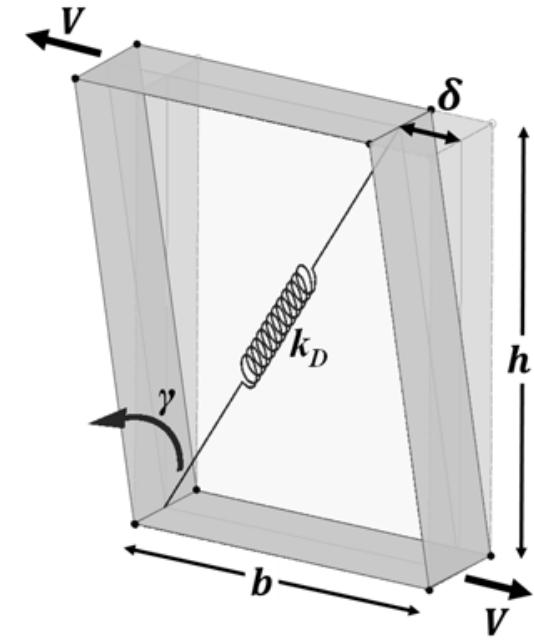

(b)

Figure 3. Calibration of diagonal link: (a) finite portion of masonry subjected to pure shear deformation, and (b) rectangular panel.

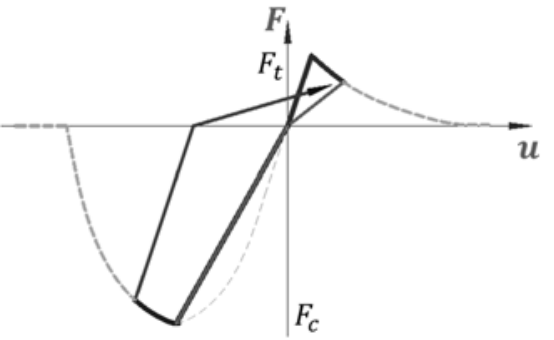

(a)

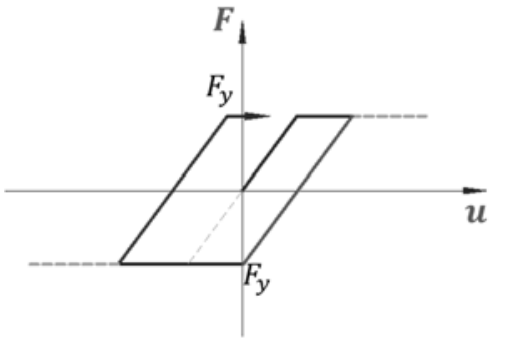

(b)

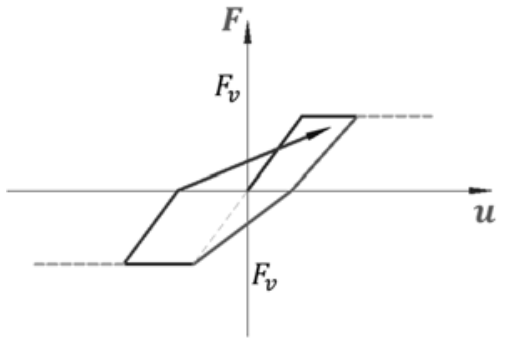

(c)

Figure 4. Constitutive models and hysteretic behavior of the different typologies of nonlinear links: (a) transversal, (b) sliding, and (c) diagonal. 


\section{Proposed procedure for seismic vulnerability assessment}

Seismic vulnerability assessment is often conducted by means of analytical fragility functions which are capable of providing the probability of a structure to reach or exceed a LS due to a given IM. A fragility curve can be described by a normal cumulative distribution function $\Phi$, which is characterized by a mean value $\theta$ and a standard deviation $\beta$ as reported in equation (6). In most investigations associated with masonry structures, the derivation of fragility curves usually involves the application of nonlinear static analyses using simplified numerical tools aiming at reducing the computational demand. Several of these formulations are based on overly simplified numerical models neglecting some relevant aspects of URM structures such as the occurrence of out-of-plane mechanisms. Aiming at obtaining more realistic results, this investigation proposes a different methodology for the assessment of URM buildings which involves the use of nonlinear static and dynamic analyses performed by means of the discrete macro-element method previously introduced.

$$
P(L S \mid I M=x)=\Phi\left(\frac{\ln (x / \theta)}{\beta}\right)
$$

The procedure for the seismic vulnerability assessment of URM structures presented in this paper involves three main activities: i) definition of seismic input, ii) definition of adequate LSs and their corresponding capacity, and iii) derivation and fitting of the fragility curves. Since the proposed modeling approach is characterized by a reduced number of DOFs, and therefore a low computational demand, the seismic vulnerability assessment is performed by nonlinear static and dynamic analyses. In this sense, it is necessary to define proper seismic accelerograms, consistent with the design spectra, which can be associated with real ground motion records as well as synthetic or artificial accelerograms (first activity). Here, accelerograms artificially generated, following specifications reported in standards, have been adopted.

For the definition of accurate capacities for the selected LSs (second activity), a novel approach, based on multidirectional pushover analyses, is 
proposed. This approach involves the application of a set of nonlinear static analyses, along different directions, with an incremental angular step as reported by Cannizzaro, et al. [41]. The result, denoted as Capacity Dominium (CD), allows the definition the displacement capacity as a function of the direction of the input for each defined LS. It is worth to note that, based on this alternative approach, different displacement-based criteria can be used for the definition of the LSs.

The derivation of the fragility curves (third activity), implies the introduction of uncertainty in the numerical model. In this investigation, the uncertainty is associated with the seismic input (scaled artificial accelerograms) and with other parameters such as mechanical properties or geometric configurations. This last activity also involved a fitting procedure for the estimation of the true probability, which considers the total number of analyses and the ones that led to the exceedance of the LS. As reported by Baker [42], a fitting process is given by a maximum likelihood approach aiming at optimizing the mean value $\theta$ and standard deviation $\beta$ that characterize the fragility function. The true probability $P$ of exceeding a LS due to the $j^{\text {th }}$ IM is given by the binomial distribution $p$ reported in equation (7) in which $z$ and $n$ correspond, respectively, to the total and exceeding number of nonlinear dynamic analyses, denoted as events hereafter. The likelihood function can be computed as the product of the binomial distributions associated with the different $m$ levels of IMs, as reported in equation (8). The fitting procedure consisted of estimating the optimum values of 363 $\theta$ and $\beta$, which provide the maximum likelihood.

$$
\begin{aligned}
& P\left(z_{j} \text { collapse in } n_{j} \text { events }\right)=\left(\begin{array}{c}
n_{j} \\
z_{j}
\end{array}\right) p_{j}{ }^{z_{j}}\left(1-p_{j}\right)^{n_{j}-z_{j}} \\
& \text { Likelihood }=\prod_{j=1}^{m}\left(\begin{array}{c}
n_{j} \\
z_{j}
\end{array}\right) \Phi\left(\frac{\ln \left(x_{j} / \theta\right)}{\beta}\right)^{z}\left(1-\Phi\left(\frac{\ln \left(x_{j} / \theta\right)}{\beta}\right)\right)^{n-z}
\end{aligned}
$$
application of multidirectional pushover analysis for the definition of the displacement capacity, and the application of extensive nonlinear dynamic analyses for the derivation of fragility curves when considering more detailed numerical models capable of considering the interaction between in-plane and out- 
of-plane mechanisms. Firstly, the CD allows a proper identification of LSs since it can be combined with different LSs criteria, and it can also be applied to any structural typology. Secondly, time history analysis constitutes a more precise tool for the assessment of the seismic response of structures since it involves energy dissipation as well as the degradation of strength and stiffness of the material.

\section{Application to a brick masonry structure}

The proposed procedure for the seismic vulnerability assessment of URM structures was applied to a brick specimen characterized by a strong out-of-plane collapse mechanism. The seismic response of such masonry structure was thoroughly investigated by means of shaking table tests [43] as well as numerical simulations [39] according to a deterministic approach. The case study and the main results previously obtained are here briefly recalled. As depicted in Figure 5 a, the considered U-shape structure was composed of three walls: a main gable and two return walls with an equal thickness of $0.235 \mathrm{~m}$. The base of the main gable wall was equal to $3.50 \mathrm{~m}$ whereas its height presented a value of $2.75 \mathrm{~m}$ at the top of the tympanum. The base and height of both return walls were equal to $2.25 \mathrm{~m}$ and $2.50 \mathrm{~m}$, respectively. This URM structure also presented two window openings: one at the main gable wall and another one at one return wall with dimensions of $0.80 \times 0.80 \mathrm{~m}^{2}$ and $0.80 \times 1.00 \mathrm{~m}^{2}$, respectively. The unusual geometry of the prototype, characterized by a U-shape plan layout, was chosen with the aim to investigate the behavior of the main gable wall taking into account the possible constraining effect of typical return walls. In the experimental campaign. the brick masonry structure was subjected to the 2011 Christchurch earthquake which was applied in the direction perpendicular to the main gable wall (Y-direction in Figure 5a). The out-of-plane behavior of the structure was also investigated by means of two numerical approaches, namely FE and Discrete Macro-Element (DME) models characterized by a different discretization, as illustrated in Figure 5b and Figure 5c respectively. The FE model was built using the DIANA software [44], and it was characterized by a rotation total strain crack model. The element type used for the FE model consisted of twenty-node bricks CHX60 which were described by a 3x3x3 integration scheme [44]. On the other 
400 hand, the DME model was implemented by means of the HiStrA software [40], 401 using the constitutive laws for the nonlinear links presented in Section 2. These 402 numerical models presented a great difference in terms of DOFs: 54477 for the FE 403 model, and 616 for the DME model. Both models were subjected to static and 404 dynamic nonlinear analyses for investigating the out-of-plane response of the 405 main gable wall. Mass proportional pushover analyses and nonlinear dynamic, 406 consistent with the seismic input recorded during the shaking table tests (see 407 Figure 5f), have been applied in the direction perpendicular to the main gable wall 408 (Y-direction in Figure 5b-c). Figure 5d shows the significant agreement between 409 the two modeling approaches when performing pushover analyses, especially in 410 the negative direction (-Y). It can be noted that there is a good agreement in 411 maximum capacity in the $+Y$-direction, but the residual forces of these two 412 modelling approaches are somehow different due to their corresponding failure 413 mechanisms. In the case of the FE model, the collapse is governed by in-plane and 414 out-of-plane mechanisms, whereas, in the case of the DME model, the response is 415 centered on the main gable wall. The comparison in terms of time history analyses 416 is depicted in Figure 5e demonstrating the capability of the proposed modeling approach of providing a satisfactory simulation of the dynamic response of a 418 sophisticated model with a strongly reduced computational burden (96\%). The 419 duration of the nonlinear dynamic analysis associated with a FE model was 420 approximately [39],Figure 5g[39]. 


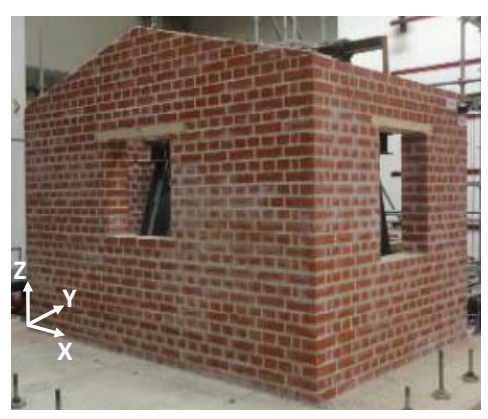

(a)

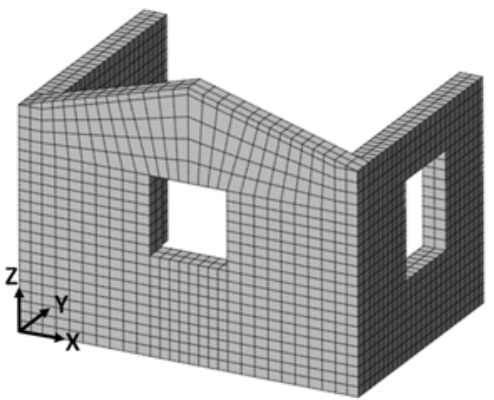

(b)

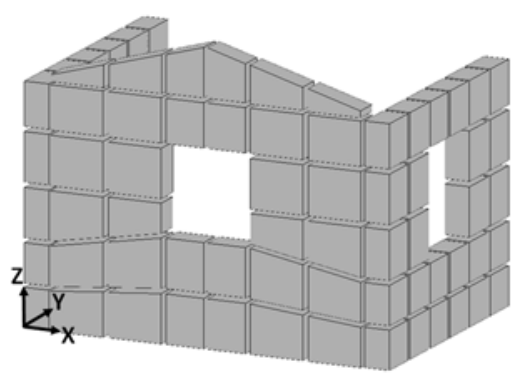

(c)

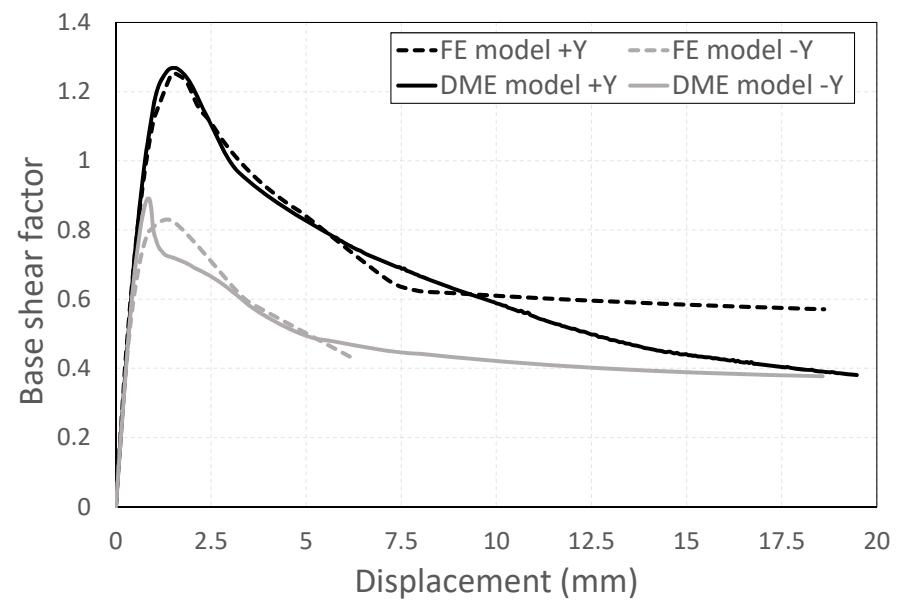

(d)

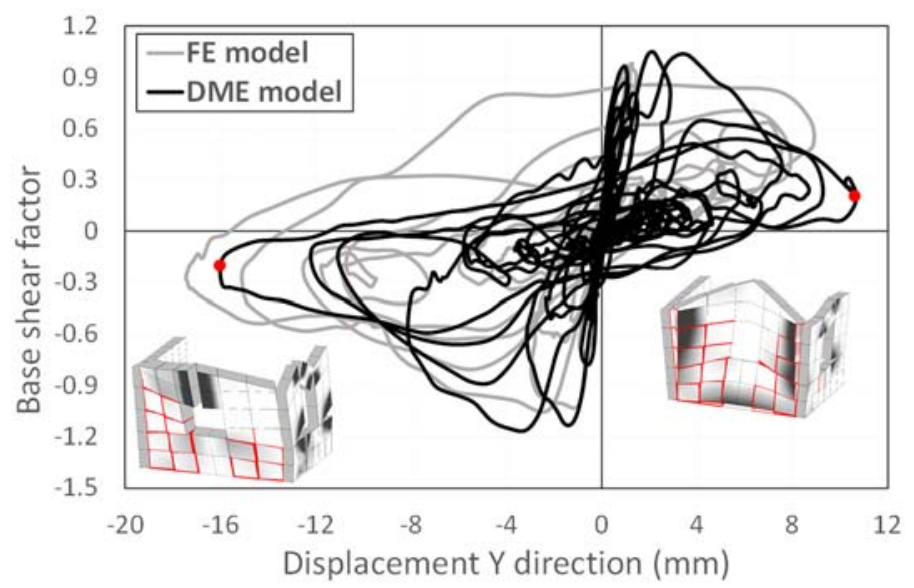

(e)

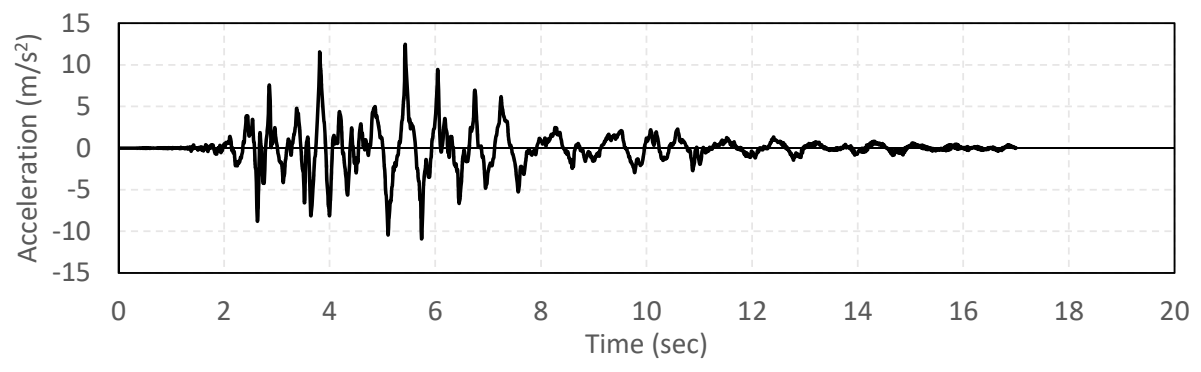

(f)

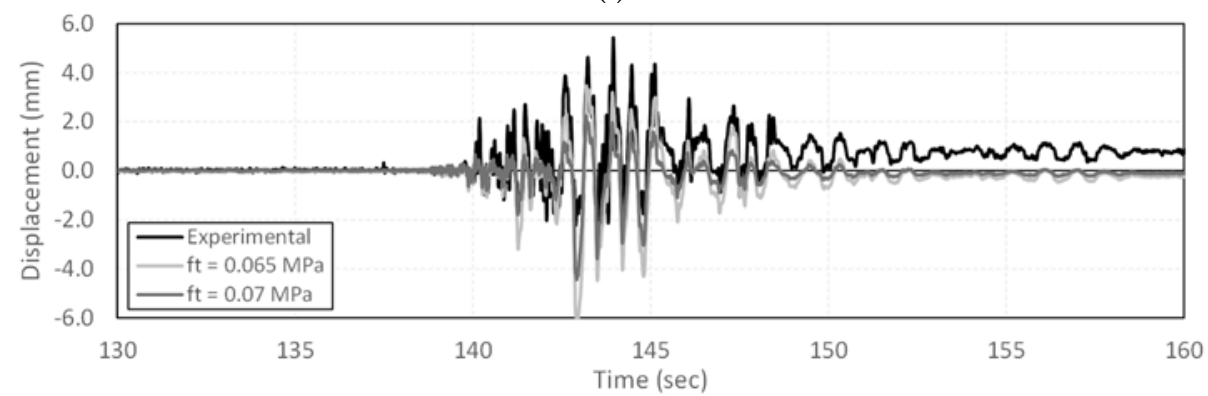

(g)

Figure 5. Brick masonry structure: (a) benchmark, (b) FE, (c) DME model, and comparison in terms of (d) pushover, (e) time history analyses , and (f) seismic input, and (g) experimental and numerical history of displacement [39]. 
447

\subsection{Step 1: Definition of seismic input}

Aiming at assessing the seismic vulnerability of the considered brick masonry structure, nonlinear dynamic analyses, performed on the DME model, have been based on uniaxial as well as three-component artificial accelerograms. The uniaxial seismic inputs have been applied in the direction perpendicular to the main gable wall in order to investigate its out-of-plane response when the excitation acts in the orthogonal direction only. The three-component artificial accelerograms have been applied to the structure to investigate the response of the gable walls under in-plane, out-of-plane and vertical base acceleration components. The artificial accelerograms were generated so that they match the horizontal and vertical elastic response spectra with $5 \%$ of viscous damping as specified by the EC8-Part1 [45]. Type 1 and Type 2 elastic response spectra, respectively associated with far- and near-field seismic inputs, were taken into consideration for this investigation. The horizontal $S_{h e}(\mathrm{~T})$ and vertical $S_{v e}(\mathrm{~T})$ components of these spectra are illustrated in Figure 6, and their definition is given in [45].

The generation of the artificial accelerograms was conducted considering a reference horizontal design ground acceleration $a_{g}$ equal to $1 \mathrm{~g}$ and $5 \%$ of viscous damping $(\eta=1)$. Assuming that the brick masonry structure was located in a Lisbon area, the soil factor $S$ was established as 1, which corresponds to a class A soil (rigid soil). The reference spectrum periods $T_{B}, T_{C}$ and $T_{D}$ were established considering the Portuguese National Annex [46]. This code also provides a ratio between vertical $\left(a_{v g}\right)$ and horizontal $\left(a_{g}\right)$ design ground accelerations. The different parameters required for the definition of the elastic response spectra Type 1 (far-field earthquakes) and Type 2 (near-field earthquakes) are summarized in Table 1.

Table 1. Parameters for the definition of horizontal elastic response spectrum.

\begin{tabular}{ccccccccc}
\hline \multirow{2}{*}{ Component } & $\begin{array}{c}\text { Elastic response } \\
\text { spectrum }\end{array}$ & Soil type & $\mathrm{S}$ & $a_{v g}$ & $H$ & $\begin{array}{c}T_{B} \\
(\mathrm{~s})\end{array}$ & $\begin{array}{c}T_{C} \\
(\mathrm{~s})\end{array}$ & $T_{D}(\mathrm{~s})$ \\
\hline \multirow{2}{*}{ Horizontal } & Type 1 & $\mathrm{~A}$ & 1 & - & 1 & 0.10 & 0.60 & 2.00 \\
& Type 2 & $\mathrm{~A}$ & 1 & - & 1 & 0.10 & 0.25 & 2.00 \\
\hline \multirow{2}{*}{ Vertical } & Type 1 & - & - & $0.75 a_{g}$ & 1 & 0.05 & 0.25 & 1.00 \\
& Type 2 & - & - & $0.95 a_{g}$ & 1 & 0.05 & 0.15 & 1.00 \\
\hline
\end{tabular}




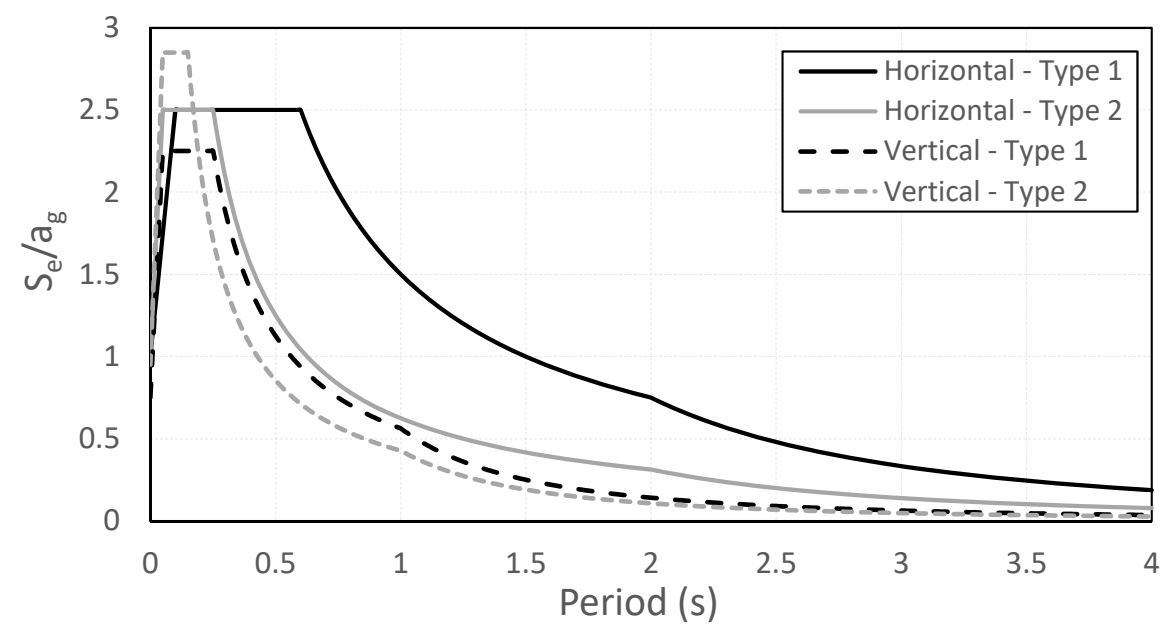

Figure 6. Elastic response spectra used for the generation of artificial accelerograms.

In addition to the elastic response spectra, the generation of artificial 449 seismic input also required the definition of minimum duration of stationary part 450 of acceleration. In accordance with the Portuguese National Annex [46], far- and near-field based artificial accelerograms are characterized by stationary times of 30 seconds and 10 seconds, respectively. In this sense, the artificial accelerograms were generated considering total durations of 40 seconds for far-field earthquakes and 20 seconds for near-field earthquakes. The generation of artificial accelerograms was conducted using the software SIMQKE [47]. An initial set of 1200 horizontal and 600 vertical samples were generated between Type 1 and Type 2 earthquakes. Since both horizontal components need to be uncorrelated, their generation was conducted separately. The accuracy of this initial set was assessed by the comparison between the spectrum of each accelerogram and the elastic response spectrum used for its generation. The artificial accelerograms whose spectrum lacked resemblance with its corresponding elastic response spectrum were discarded from the initial set. The selection of suitable samples led to a final set of 560 horizontal and 280 vertical artificial accelerograms which were subsequently subjected to a baseline correction by means of the software LNECSPA [48]. A high pass Fourier filter of $0.20 \mathrm{~Hz}$ and a cosine-based windowing approach were considered for the signal processing of the accelerograms. 
The definition of appropriate limit states LSs constitutes a relevant task

469

470

471

472

473

474

475

476

477

478

479

480

481

482

483

484

485

486

487

488

489

490

491

492

493

494

495

496

497 for seismic vulnerability assessment. The LSs can be evaluated considering the capacity of a structure in terms of interstory drift, damaged area, hysteretic energy or base-shear resistance. From the different approaches, the assessment of the seismic vulnerability of masonry structures is usually conducted based on interstory drift procedures. For instance, the EC8-Part3 [9] establishes three LSs, namely Damage Limitation, Significant Damage and Near Collapse, together with their corresponding displacement capacity. The capacity associated with the first LS is given by the yielding displacement, whereas the definition of the capacity related to the second LS depends on the type of failure mechanism, namely flexural and shear. The capacity of the remaining LS (Near Collapse) is defined as $4 / 3$ of the drift associated with a Significant Damage LS. Nevertheless, the definition of these interstory drift capacities is related to masonry structures with a box-type behavior; and therefore, they are not suitable for structures with predominant out-of-plane collapse mechanisms. The multiscale approach proposed in $[17,18]$ may be considered as a proper formulation for the definition of LSs of the masonry structure under investigation; however, due to its predominant out-of-plane behavior as well as its irregular geometrical characteristics, it was decided to adopt an alternative procedure. In this regard, the CD constitutes a tool that enables the evaluation of the global response of the structure allowing a comprehensive representation of the capacity of the building and a proper identification of LSs.

The EC8-Part3 [9] and the Italian Code [11] relate the definition of LSs to the base shear of the structure. These LSs, namely Near Collapse for the former and Life Safety for the latter, are established when a structure experiences a 20\% loss of its maximum shear resistance (ultimate displacement). For the proposed methodology, such shear capacity based formulation was taken into consideration for the definition of two of the LSs, namely Near Collapse and Significant Damage. The definition of the first LS (Damage Limitation) was given by the yielding displacement as specified in the EC8-Part 3 [9]. A summary of the LSs used in this 
investigation, together with their corresponding displacement capacity, is

499 reported in Table 2.

Table 2. Limit states and displacement capacity for the assessment of the seismic vulnerability of the brick masonry structure.

\begin{tabular}{cc}
\hline Limit State & Capacity definition \\
\hline Damage Limitation & $u_{y}$ (yielding displacement) \\
Significant Damage & $3\left(u_{u}\right) / 4$ \\
Near Collapse & $u_{u}$ (ultimate displacement at $20 \%$ reduction of capacity) \\
\hline
\end{tabular}

In the proposed methodology, the definition of the displacement capacity

501 of the LSs involves the application of an alternative procedure denoted as Capacity

502 Dominium (CD) [49]. In this procedure, the structure is subjected to a set of 503 nonlinear static analyses along different angles aiming at assessing its global 504 response. For this investigation, the brick masonry structure was subjected to a 505 set of sixteen analyses with an incremental angular step of $22.5^{\circ}$ as illustrated in 506 Figure 7. These analyses were performed by applying an incremental force 507 proportional to the mass in each direction. The mechanical properties of the DME 508 model were adopted according to [39] which are reported as the mean values in 509 Table 3. The global response of the structure was evaluated by considering the 510 control nodes with highest out-of-plane displacements: one located at the top of 511 the tympanum and two placed at the top of the end of both return walls.

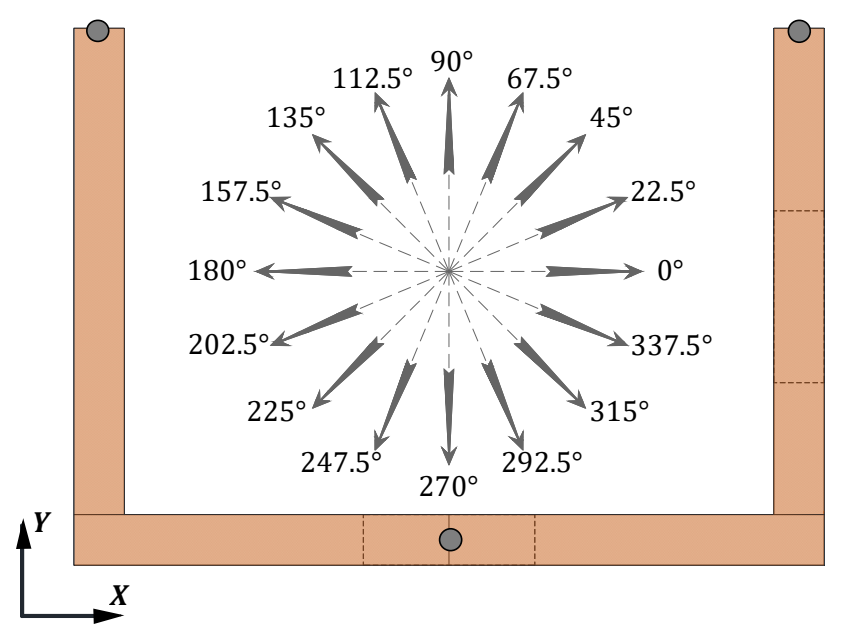

Figure 7. Application of nonlinear static analyses for the definition of the LSs based on a Capacity Dominium procedure. 
513 sixteen pushover curves until a $20 \%$ loss of maximum shear capacity was attained.

514 As illustrated in Figure 8a, the pushover curves were plotted backward, along

515 their corresponding angles, and at an equal distance of $8 \mathrm{~mm}$ from the origin $\mathbf{O}$.

516 Subsequently, patches were employed to connect each pushover curves aiming at

517 the definition of a color map basket domain (see Figure 8b) which corresponds to

518 a three-dimensional representation of the global capacity of the brick masonry

519 prototype. In Figure 8, the vertical axis is associated with the load factor (ratio

520 between base shear and self-weight), whereas the horizontal axes are related to

521 the horizontal displacements in $\mathrm{X}$ and $\mathrm{Y}$ directions, respectively.

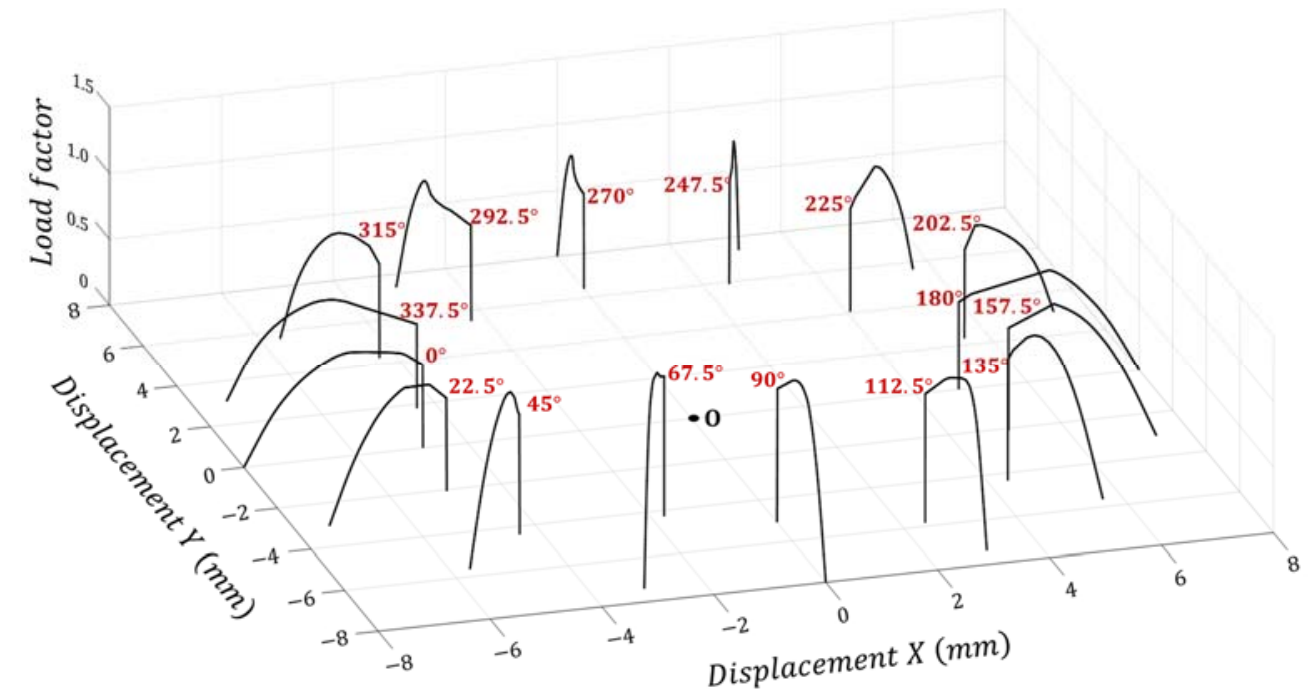

(a)

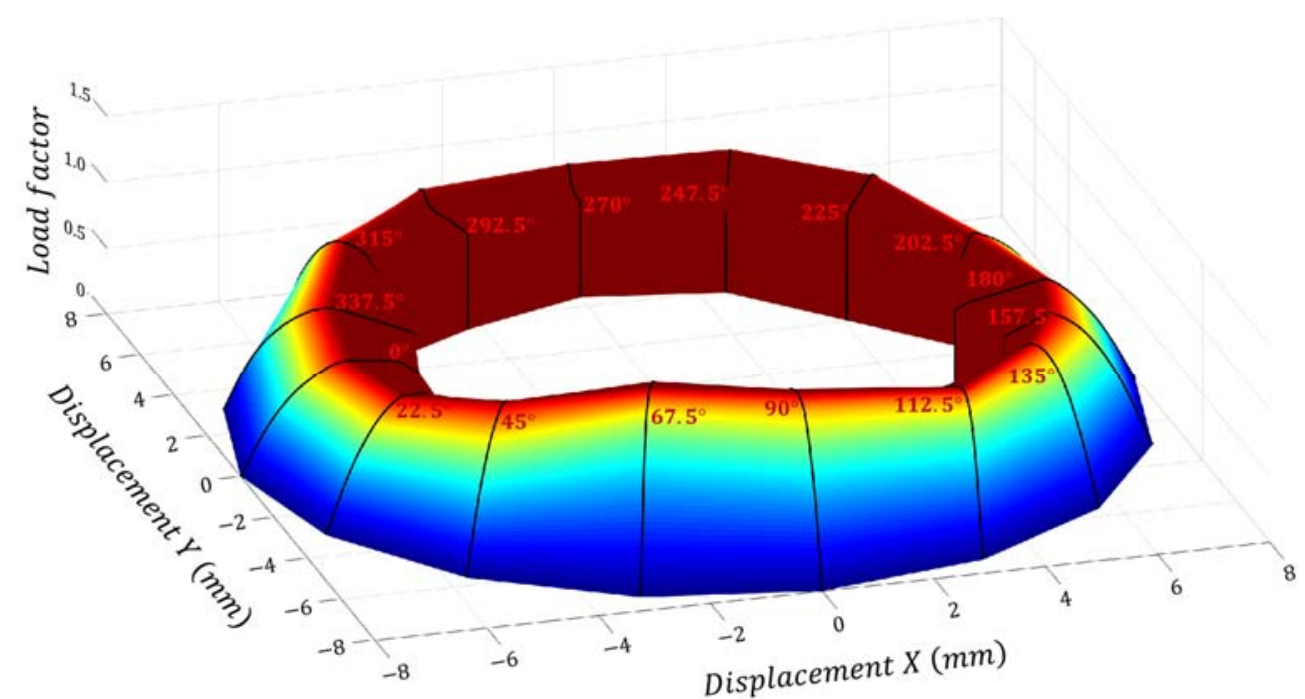

(b)

Figure 8. Construction of basket domain based on the application of pushover analyses along different angles. 
523 effective displacement field in the three-dimensional basket domain as shown in

524 the gray area in Figure 9a. Such displacement field is created by connecting a set

525 of nodes in accordance with the different pushover curves and their corresponding 526 angle plotted in the three-dimensional basket domain. These contouring nodes are

527 located at a distance $d_{a}$ equal to the ultimate horizontal displacement from the 528 origin O. Following a similar approach and considering the specifications provided 529 by the EC8-Part3 [9], the CD for the two additional LSs were also properly 530 established. In the case of the Damage Limitation LS, the displacement field was 531 associated with the yielding displacement and it is given by the blue area in Figure 532 9b. The CD for a Significant Damage LS was defined as a ratio of $3 / 4$ with respect 533 to the Near Collapse LS (red area in Figure 9b) as stated by the EC8-Part3 [9]. It 534 is remarkable how the CDs change shape as a function of the LS. As an example, 535 the $+\mathrm{X} /-\mathrm{Y}$ sector is rather stringent in terms of Damage Limitation LS, while the $536-\mathrm{X} /-\mathrm{Y}$ sector becomes rather stringent for the Significant Damage and Near 537 Collapse LSs, when compared with the remaining LSs in the same sector. This 538 behavior can be associated with the presence of a window opening in one return 539 wall which introduces asymmetry to the structure. In addition, it is possible to 540 notice that different shapes of the CDs in the $-\mathrm{Y}$ and $+\mathrm{Y}$ sectors. These different

541 shapes are given by the asymmetry generated by the window openings but also by 542 the influence of the return walls on the global stiffnesses of the structure and their 543 capacity to deform. 


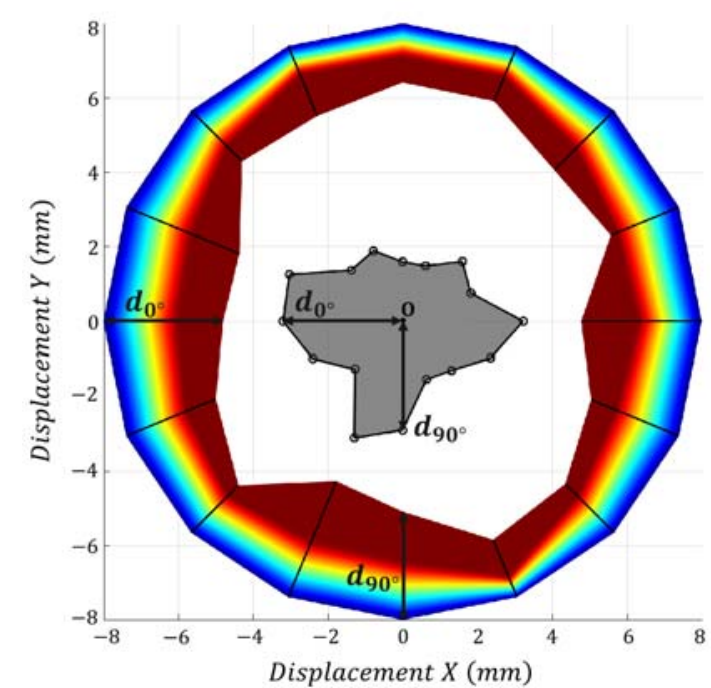

(a)

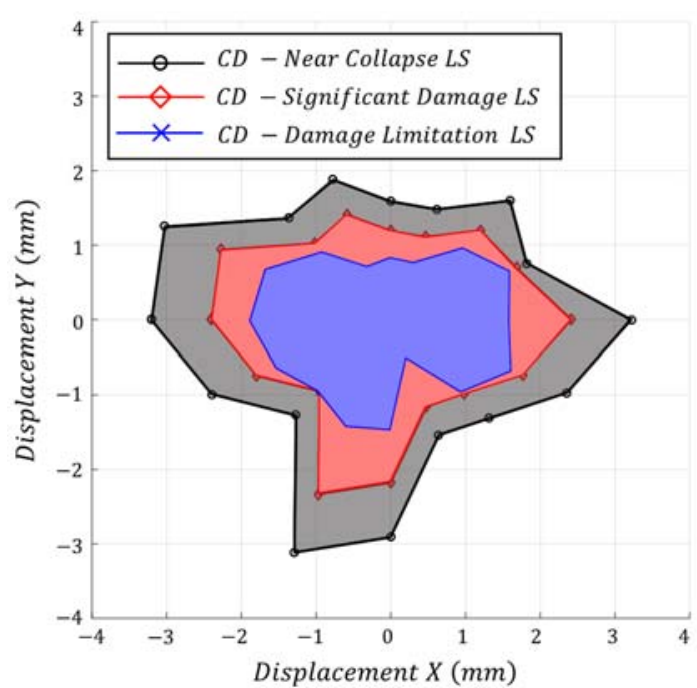

(b)

Figure 9. Displacement capacity: (a) creation of effective displacement field, and (b) Capacity Dominium for the selected LSs.

\subsection{Step 3: Derivation and fitting of analytical fragility curves}

In this work, the seismic vulnerability of the masonry structure was assessed by the derivation of analytical fragility curves through the application of nonlinear dynamic analyses. For this purpose, the DME model of this prototype was subjected to artificial accelerograms compatible with the design spectra. Although the generation of the seismic input constitutes a significant source of uncertainty, it is necessary to consider different sources of uncertainty in order to conduct a more reliable seismic vulnerability assessment. These additional uncertainties have been mainly focused on mechanical properties which require the definition of probability density functions (PDFs) together with mean values and coefficients of variation (COVs). The mean values and COVs of material properties such as Young's modulus $E$, specific weight $\gamma$, compressive $f_{c}$, and tensile $f_{t}$ strength, were established based on the mechanical characterization conducted by Candeias, et al. [43]. In such investigation, simple and diagonal compression tests were conducted to the brick masonry in order to determine the latter mechanical properties as well as their statistical characteristics. The mean values of other mechanical properties, namely, tensile fracture energy $G_{f} I$, shear modulus $G$, shear strength $f_{y 0}$, cohesion $c$, and friction coefficients associated with the diagonal and sliding failure modes $\left(\mu_{d}\right.$ and $\left.\mu_{s}\right)$, were defined as the parameters presented in the seismic assessment of the brick masonry structure conducted in 
564 [39]. On the other hand, the mean values of the fracture energies in compression $565 G_{c}$ and shear-sliding $G_{f} f^{I I}$, were given as a function of ductility indexes as reported 566 in literature. For instance, Lourenço [50] provided average values for ductility 567 indexes in compression $d_{u c}$ and shear-sliding $d_{u s}$ equal to $1.6 \mathrm{~mm}$ and $0.09 \mathrm{~mm}$, 568 respectively. The definition of $\mathrm{COVs}$ for the mechanical properties associated with 569 the shear mechanisms (diagonal and sliding) followed the specifications provided 570 by the JCSS Probability Model Code [51]. In the case of shear strength and 571 cohesion, the COV presented a value of $40 \%$, whereas, in the case of friction 572 coefficients, this value was equal to $19 \%$. Due to the lack of information related to 573 the remaining mechanical properties, it was assumed that their corresponding 574 COVs corresponded to $30 \%$. The statistical characteristics for the mechanical 575 properties are summarized in Table 3. In this investigation, the uncertainty was 576 also focused on other geometrical and structural parameters such as thickness and 577 viscous damping ratio. In the case of the wall thickness, a mean value of $23.5 \mathrm{~cm}$ 578 and a COV of $5 \%$ were established as statistical characteristics. The viscous 579 damping ratio presented a mean value of $3 \%$, and due to the lack of information 580 associated with this structural parameter for URM structures, it was assumed 581 that it presented a $\mathrm{COV}$ of $30 \%$. It is worth to note that the different uncertain 582 parameters (mechanical, geometrical and structural) were characterized by a 583 lognormal PDF.

Table 3. Probabilistic models associated with the mechanical properties of the DME model.

\begin{tabular}{|c|c|c|c|c|c|}
\hline & Parameter & & & Mean & Coefficient of Variation \\
\hline \multirow{3}{*}{$\begin{array}{c}\text { Elastic } \\
\text { behavior }\end{array}$} & Young's modulus & $E$ & $\mathrm{~N} / \mathrm{mm}^{2}$ & 5170 & $29 \%$ \\
\hline & Shear modulus & $G$ & $\mathrm{~N} / \mathrm{mm}^{2}$ & 2133 & $30 \%$ \\
\hline & Specific weight & $\Gamma$ & $\mathrm{N} / \mathrm{mm}^{3}$ & $18.9 \times 10^{-6}$ & $3 \%$ \\
\hline \multirow{2}{*}{$\begin{array}{c}\text { Tensile } \\
\text { behavior }\end{array}$} & Tensile strength & $f_{t}$ & $\mathrm{~N} / \mathrm{mm}^{2}$ & 0.1 & $19 \%$ \\
\hline & Fracture energy & $G_{f}^{I}$ & $\mathrm{~N} / \mathrm{mm}$ & 0.012 & $30 \%$ \\
\hline \multirow{2}{*}{$\begin{array}{c}\text { Compressive } \\
\text { behavior }\end{array}$} & Compressive strength & $f c$ & $\mathrm{~N} / \mathrm{mm}^{2}$ & 2.48 & $14 \%$ \\
\hline & $\begin{array}{l}\text { Compressive ductility } \\
\text { index }\end{array}$ & $d_{u c}$ & $\mathrm{~mm}$ & 1.6 & $30 \%$ \\
\hline \multirow{3}{*}{$\begin{array}{l}\text { Shear- } \\
\text { sliding } \\
\text { behavior }\end{array}$} & Cohesion & $c$ & $\mathrm{~N} / \mathrm{mm}^{2}$ & 0.1 & $40 \%$ \\
\hline & Friction coefficient & $\mu_{s}$ & - & 0.7 & $19 \%$ \\
\hline & $\begin{array}{l}\text { Shear-sliding ductility } \\
\text { index }\end{array}$ & $d_{u s}$ & $\mathrm{~mm}$ & 0.09 & $30 \%$ \\
\hline & Shear strength & $f_{y 0}$ & $\mathrm{~N} / \mathrm{mm}^{2}$ & 0.07 & $40 \%$ \\
\hline
\end{tabular}


Shear-

diagonal

behavior

The seismic vulnerability of the brick masonry structure was initially

585

586

587

588

589

590

591

592

593

594

595

596

597

598

599

600

601

602

603

604

605

606

607

608

609

610

611

612

613 evaluated through the application of a set of 2000 time-history analyses based on uniaxial artificial accelerograms (along the $\mathrm{Y}$ direction, perpendicular to the main gable wall). From this initial set, 1000 analyses were associated with far-field seismic input (Type 1), whereas the remaining 1000 were related to near-field seismic input (Type 2). Each of these sets was subsequently divided into eight groups of 125 analyses in order to consider different intensity levels of PGA. Since the artificial accelerograms were generated with a horizontal design acceleration equal to $1 \mathrm{~g}$, it was necessary to scale them aiming at comprising a wide range of PGA. In this case, eight scaling factors ranging between 0.45 and 0.80 (with an incremental step of 0.05) were defined for the seismic vulnerability assessment of the brick masonry structure. In order to define the uniaxial seismic inputs, 125 horizontal components were randomly selected from the corresponding final set of artificial accelerograms generated in Section 4.1. Subsequently, 125 random values of the different uncertain geometrical and mechanical parameters were defined based on their corresponding mean value, COV, and PDF. It is worth noting that the computational demand required for the assessment of the seismic vulnerability assessment of this structure was acceptable since the average duration of a single analysis was about 30 minutes using a conventional desktop.

An automatic routine was implemented for the application of time history analyses considering the variability of seismic inputs and uncertain parameters. The structural damping was assigned based on a Rayleigh criterion by considering natural frequencies of $18.8 \mathrm{~Hz}$ and $75.4 \mathrm{~Hz}$ as reported in [39]. These values were obtained after an eigenvalue analysis considering the mean values of the initial mechanical properties, and they remained constant despite the variation of properties such as the Young's modulus since it would require additional computational burden for the estimation of the dynamic properties for each time history analysis. Moreover, it is worth noticing that the contribution of viscous damping can be considered negligible if compared to the hysteretic dissipation considering the high non-linearity characterizing the structural response. The 
614 definition of the mass properties of the numerical model was based on an efficient

615 diagonal mass matrix as reported in [52].

616 The CD related to each LSs, introduced in the previous sub-section, has

617 been obtained by analyzing the nonlinear response of the prototype when

618 subjected to static loading. The identification of the exceedance of a certain LS

619 when the structure is subjected to dynamic loading is not straightforward since

620 the displacement capacity of a structure subjected to earthquake dynamic loading

621 is generally higher, when compared to the corresponding capacity obtained for a

622 monotonic application of horizontal static loads. For this reason, it is necessary to

623 establish a conventional criterion for the exceedance of each LS. In the application

624 here performed in order to conduct the maximum likelihood fitting process, it has

625 been assumed that an exceeding event is given when the history of the horizontal

626 top displacements exceeds the area of its corresponding CD at least twice (a single

627 event is disregarded, while a second event is assumed as a confirmation. Initially,

628 the seismic vulnerability assessment was carried out considering that an event

629 exceeded a given LS when the dynamic response surpassed the CD at least once.

630 However, a single time could be considered as an impact or outlier caused by the

631 seismic input and not as the real collapse of the structure. Therefore, the events

632 in which the dynamic response remained inside the CD or surpassed only once the

633 displacement field were not included in the fitting procedure.

634 The assessment of the dynamic response due to the application of Type 2

635 uniaxial seismic input is illustrated throughout Figure 10 for the three LSs

636 defined for this investigation. In this figure, the responses associated with each of

637 the three control nodes selected for the definition of the CD were plotted together.

638 As it was expected, the dynamic response of the numerical model was strongly

639 characterized by histories of displacements in the Y direction (node at the top of

640 the main gable wall), since the seismic input was applied only in that direction.

641 The response of the other two control nodes did not present a significant

642 displacement since the dynamic load was applied in one direction. The assessment

643 was focused on the out-of-plane behavior of the façade; therefore, only the results

644 associated with the top of the tympanum as control node were considered for the 


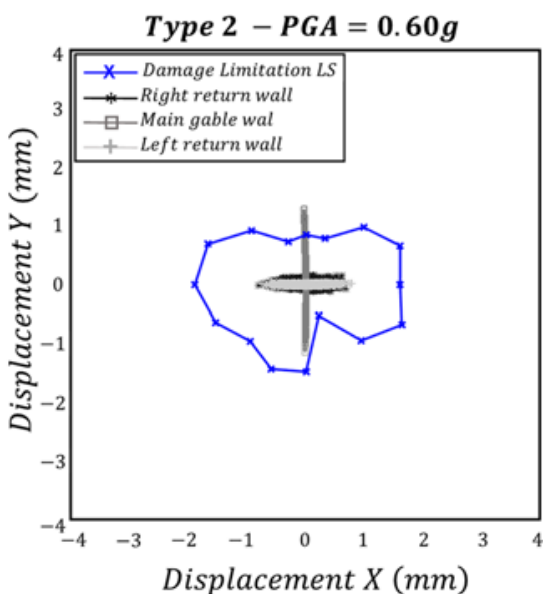

(a)

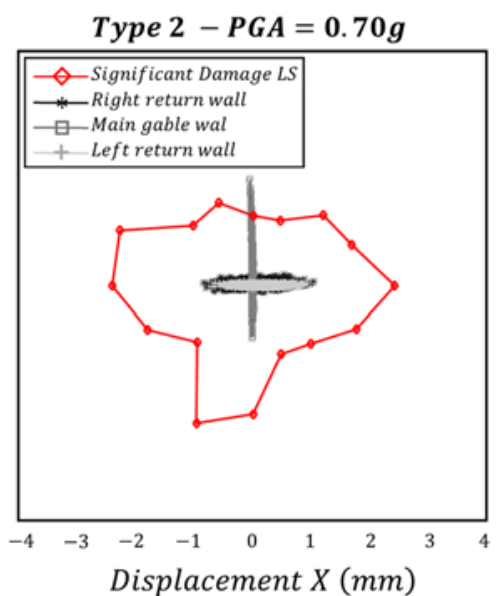

(b)

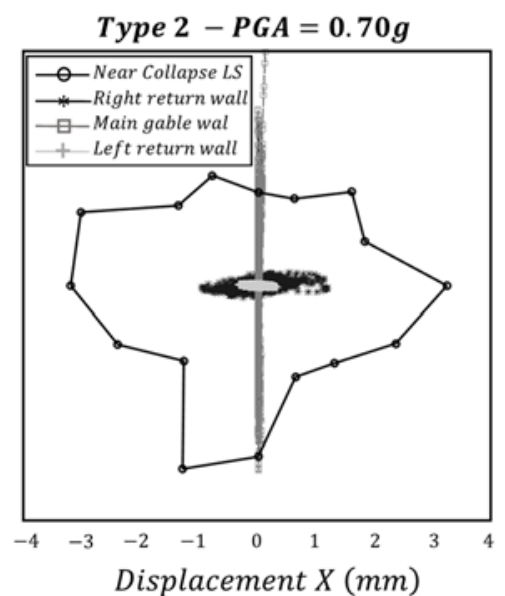

(c)

Figure 10. Assessment of seismic performance based on a Capacity Dominium due to the application of uniaxial artificial accelerograms to different LSs:

(a) Damage Limitation , (b) Significant Damage, and (c) Near Collapse.

647

Table 4. Exceeding events for the derivation of analytical fragility curves due to the application of uniaxial artificial accelerograms (out of a set of 125).

\begin{tabular}{cccccccc}
\hline & Number & \multicolumn{6}{c}{ Number of exceeding events } \\
\cline { 3 - 8 } IM & $\begin{array}{c}\text { of } \\
\text { events }\end{array}$ & Damage Limitation LS & \multicolumn{2}{c}{ Significant Damage LS } & \multicolumn{2}{c}{ Near Collapse LS } \\
\hline $0.45 \mathrm{~g}$ & 125 & 32 & Type 2 & Type 1 & Type 2 & Type 1 & Type 2 \\
$0.50 \mathrm{~g}$ & 125 & 51 & 35 & 19 & 26 & 13 & 6 \\
$0.55 \mathrm{~g}$ & 125 & 81 & 50 & 37 & 55 & 26 & 14 \\
$0.60 \mathrm{~g}$ & 125 & 96 & 74 & 57 & 89 & 68 & 24 \\
$0.65 \mathrm{~g}$ & 125 & 106 & 92 & 73 & 106 & 79 & 59 \\
$0.70 \mathrm{~g}$ & 125 & 116 & 102 & 92 & 110 & 92 & 72 \\
$0.75 \mathrm{~g}$ & 125 & 122 & 110 & 99 & 116 & 108 & 91 \\
$0.80 \mathrm{~g}$ & 125 & 123 & 115 & 110 & 120 & 112 & 99 \\
\hline
\end{tabular}

648

649

650

651

652

653

654

655

656

657

The fitted analytical fragility curves obtained from the application of uniaxial artificial accelerograms are illustrated in Figure 11. From these results, it is possible to determine the probability of exceedance of a LS due to the occurrence of a seismic event with a given value of PGA. In the case of far-field earthquakes, there is a $44 \%$ of probability of exceeding the Damage Limitation LS when the brick masonry structure is subjected to a seismic intensity of $0.50 \mathrm{~g}$ (see solid lines in Figure 11). This probability reduces to $31 \%$ and $22 \%$ when considering the Significant Damage and Near Collapse LSs, respectively. In a similar way, it is also possible to estimate the expected seismic intensity in terms of PGA for a desired probability of exceedance. For instance, the Damage 
658 Limitation LS is exceeded with a probability of $50 \%$ when the PGA of the seismic

659 input corresponds to approximately $0.52 \mathrm{~g}$. In the case of the remaining LSs, the 660 expected intensity of the uniaxial seismic input increases to $0.57 \mathrm{~g}$ and $0.61 \mathrm{~g}$. It 661 was also observed that the analytical fragility curves of the different LSs obtained 662 from the application of uniaxial far-field seismic inputs were not so separated. 663 Such behavior is strictly related to the characteristics of the CD and the definition 664 of the capacity of the LSs since the displacement fields were close to each other as 665 a result of the rapid loss of shear resistance and the quasi-brittle behavior of the 666 material, as a consequence of the low-ductility capacity of the structure. The 667 dashed lines in Figure 11 illustrate the analytical fragility curves associated with 668 the application of near-field seismic input. In this case, the probabilities of 669 exceedance of the different LSs were also estimated considering a seismic intensity 670 of 0.50 g. For a Damage limitation LS, this probability corresponds to $42 \%$ which 671 is slightly lower when comparing it to the one obtained with far-field seismic 672 inputs. A stronger reduction was observed for the Significant Damage and Near 673 Collapse LSs. In the former, the probability of exceedance presents a value of $22 \%$, 674 whereas, in the latter, such probability corresponds to $11 \%$. In these cases, the 675 reduction between far- and near-field probabilities is around $10 \%$, and it may also

676 be related to the characteristics of the seismic input such as frequency content and 677 stationary time.

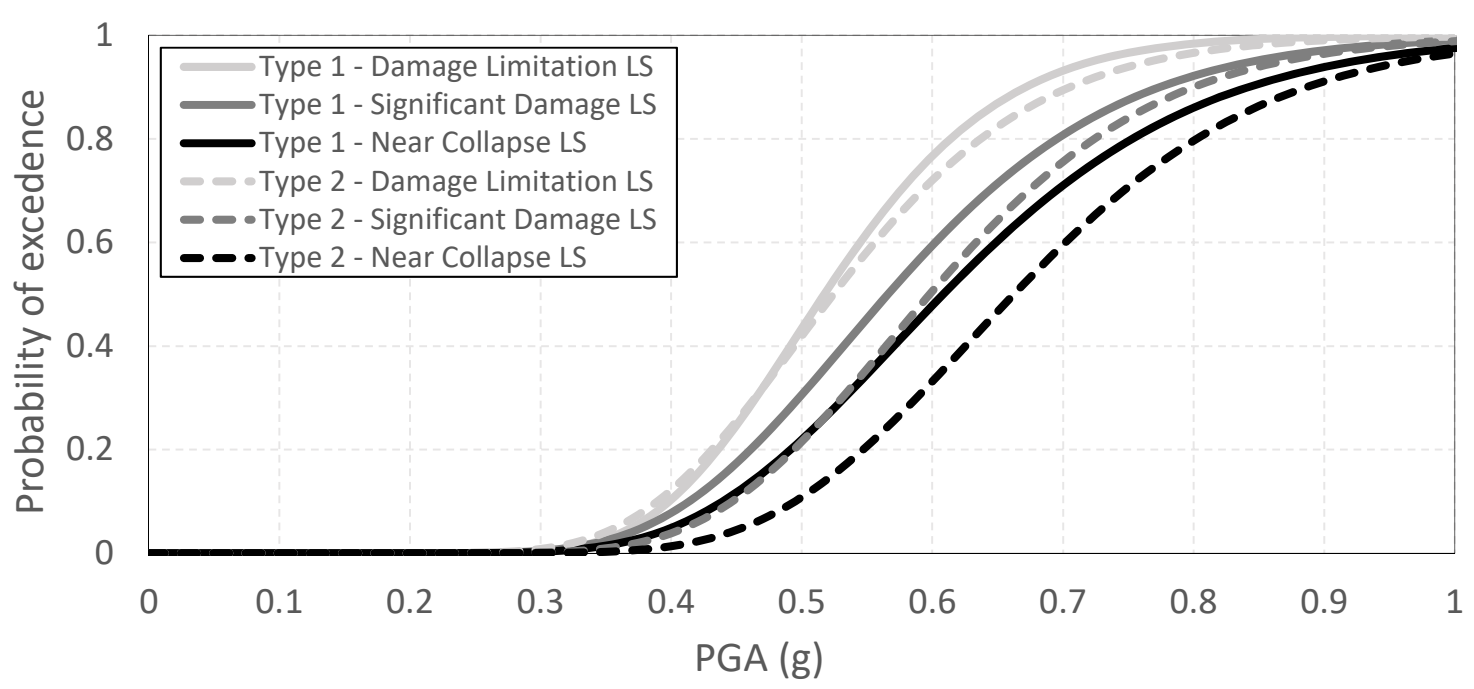

Figure 11. Analytical fragility curves derived due to the application of uniaxial artificial accelerograms. 
A sensitivity analysis was conducted regarding the role that plays the 679 times that the dynamic response surpasses the CD on the total number of 680 exceeding events. As illustrated in Figure 12a, it can be stated that, when 681 considered Type 1 seismic inputs, the analytical fragility curves do not present 682 significant changes if three or four events are considered. On the contrary, the 683 number of times that the dynamic response is outside the displacement capacity 684 plays a slight influence when applying artificial accelerograms based on a Type 2 685 earthquakes (see Figure 12b). In the case of an IM equal to $0.60 \mathrm{~g}$, the probability 686 of exceeding a Damage Limitation LS presented a reduction of $6.4 \%$ when 687 considering that the dynamic response is out of the CD at least four times. A 688 similar behavior was noticed in the case of the remaining two LSs: reductions of $6895.5 \%$ and 5.7\% for a Significant Damage and Near Collapse LSs, respectively. It is 690 worth noting that these may be considered as small reduction. Nevertheless, 691 further investigations regarding the optimum number of times that the dynamic 692 response should be outside the displacement capacity need to be conducted. In 693 addition, different criteria can also be used for considering the overcapacity of the 694 structure when subjected to dynamic loadings. The stabilizing effect of the inertial 695 force distributions could be considered by accounting for a dynamic amplification 696 factor of the static dominium. This additional alternative approach also requires 697 further experimental data and will be the subject of future investigations. 


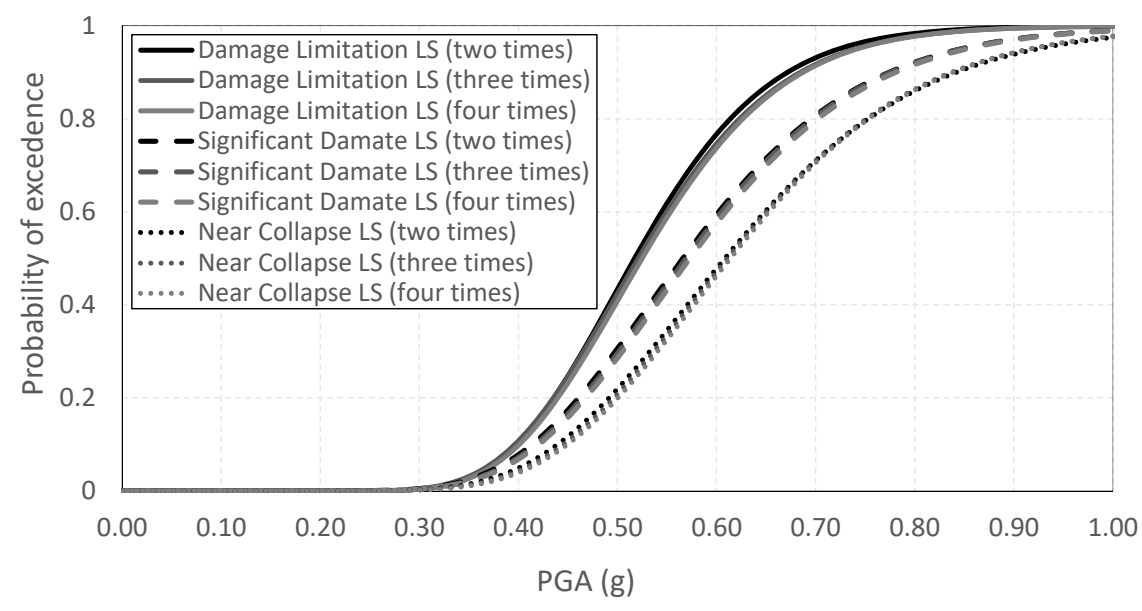

(a)
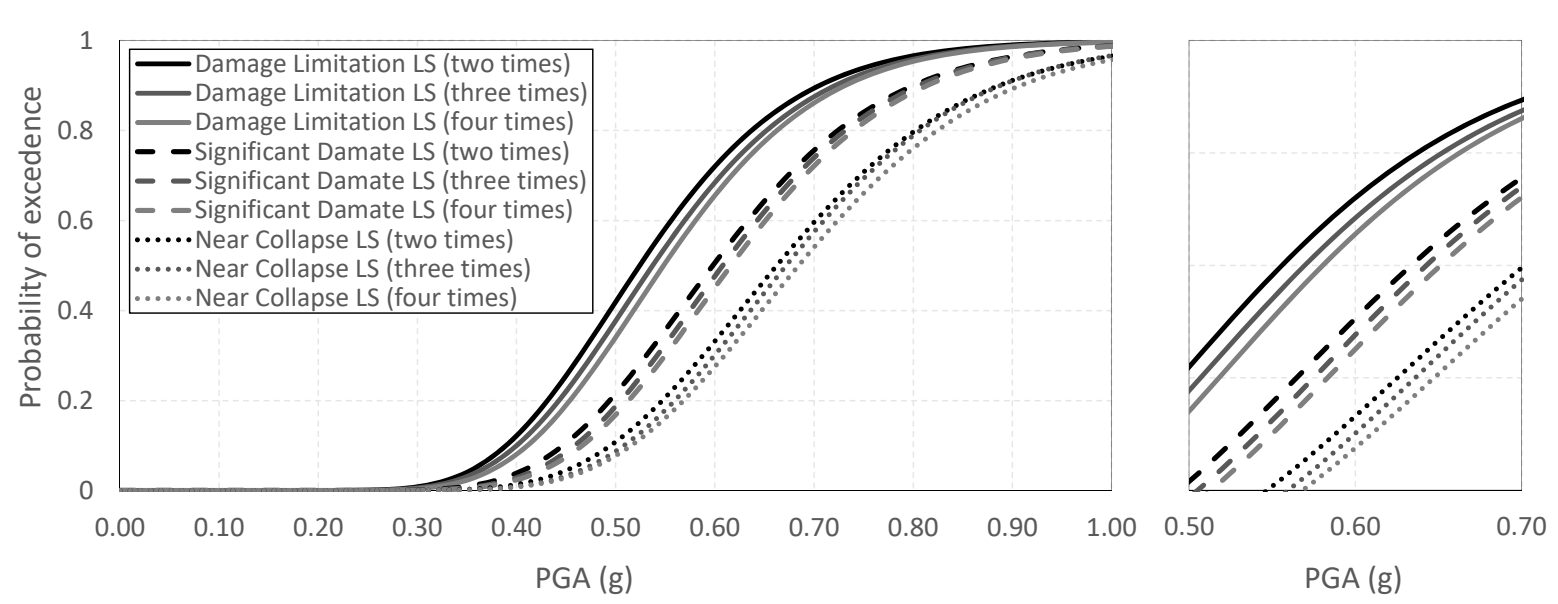

(b)

Figure 12. Sensitivity analysis regarding the number of times that dynamic response was outside the displacement capacity: (a) Type 1 and (b) Type 2 seismic inputs.

Following the same approach, the seismic vulnerability of the brick masonry structure was also assessed considering the influence of additional components of acceleration (horizontal and vertical). Another set of 2000 analyses was applied to the numerical model equally distributed between far- and near-

702 field seismic inputs with a range of PGA between $0.45 \mathrm{~g}$ and $0.8 \mathrm{~g}$. For this assessment, it was also required to define 125 three-component artificial accelerograms together with 125 uncertain parameters related to the mechanical properties. The time history analyses were conducted using the automatic routine considering the new variability of artificial accelerogram. This evaluation was also focused on the out-of-plane response of the main gable wall, assuming a proper 
neglected when assessing the seismic vulnerability of the brick masonry structure.

710 Again, the dynamic response in terms of history of horizontal displacements at the

711 top of the gable wall has been evaluated by means of the CD in order to determine 712 the number of exceeding events for each of the LSs.

713 Figure 13 reports the displacement histories of the three control nodes

714 together with the CD of the different LSs due to the application of three-

715 component artificial accelerograms. It can be evidenced that this multi-directional

716 approach is a powerful tool since it allows the evaluation of the different control

717 nodes with respect to the different LSs. It can be noted that the response of this

718 typology of structure does not only experience displacement in the $\mathrm{Y}$ direction

719 (main gable wall), but also in the $\mathrm{X}$ direction (return walls) due to the additional

720 component of acceleration. This response is mainly associated with the

721 geometrical characteristics of this structure (U-shape configuration) that implies

722 that the two unconstrained return walls experience an important out-of-plane

723 response. Nonetheless, in this study, the seismic vulnerability assessment was

724 conducted considering only the dynamic response associated with the gable wall

725 and its out-of-plane response, coherently with the experimental campaign. This

726 assumption was also based on the fact that in actual buildings, the return walls

727 are restrained by additional structural elements which limit the out-of-plane

728 response at the corners. After the evaluation of the dynamic response associated

729 with a single control node, it was possible to determine the number of exceeding 730 events which are summarized in Table 5. 


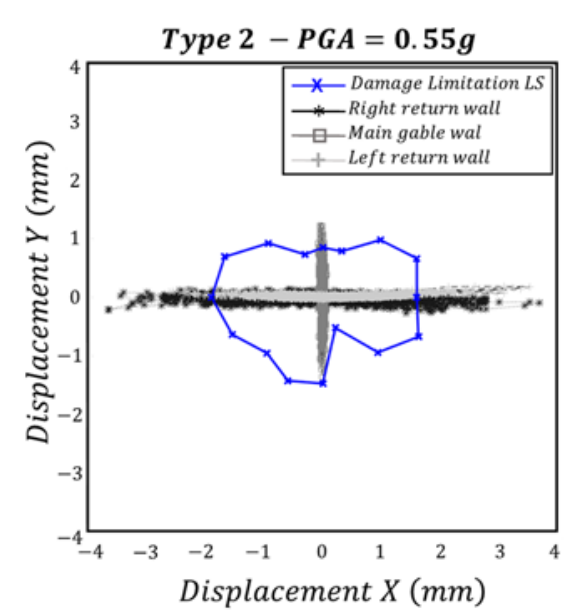

(a)

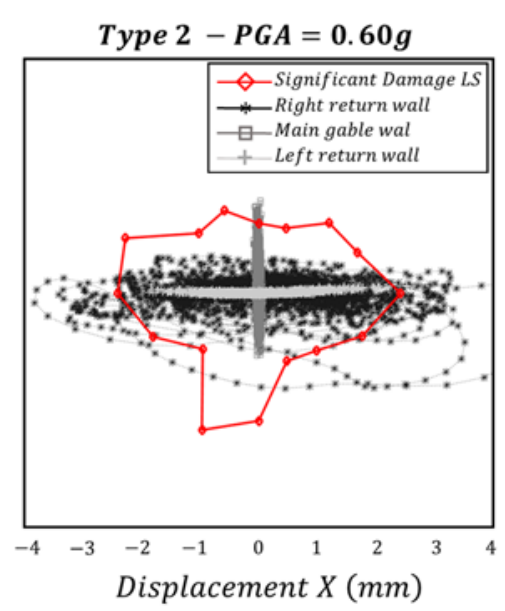

(b)

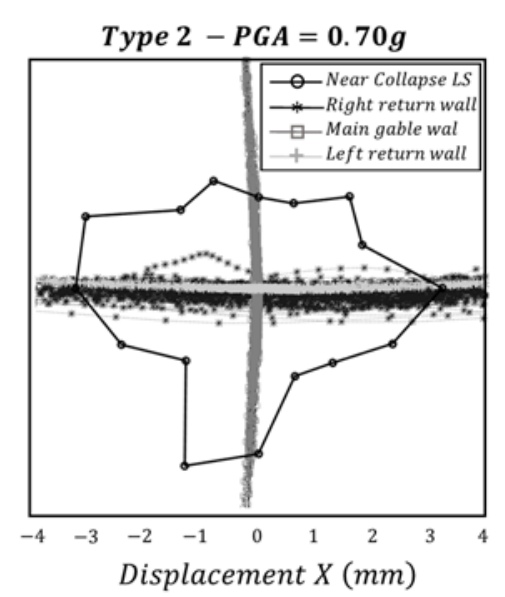

(c)

Figure 13. Assessment of seismic performance based on a Capacity Dominium due to the application of three-component artificial accelerograms: (a) Damage Limitation, (b) Significant Damage, and (c) Near Collapse LSs.

Table 5. Exceeding events for the derivation of analytical fragility curves due to the application of three-component artificial accelerograms (out of a set of 125).

\begin{tabular}{|c|c|c|c|c|c|c|c|}
\hline \multirow{3}{*}{ IM } & \multirow{3}{*}{$\begin{array}{c}\text { Number } \\
\text { of } \\
\text { events }\end{array}$} & \multicolumn{6}{|c|}{ Number of exceeding events } \\
\hline & & \multicolumn{2}{|c|}{ Damage Limitation LS } & \multicolumn{2}{|c|}{ Significant Damage LS } & \multicolumn{2}{|c|}{ Near Collapse LS } \\
\hline & & Type 1 & Type 2 & Type 1 & Type 2 & Type 1 & Type 2 \\
\hline $0.45 \mathrm{~g}$ & 125 & 79 & 72 & 57 & 38 & 43 & 21 \\
\hline $0.50 \mathrm{~g}$ & 125 & 104 & 99 & 85 & 70 & 67 & 43 \\
\hline $0.55 \mathrm{~g}$ & 125 & 113 & 108 & 104 & 92 & 89 & 74 \\
\hline $0.60 \mathrm{~g}$ & 125 & 121 & 117 & 116 & 108 & 107 & 97 \\
\hline $0.65 \mathrm{~g}$ & 125 & 124 & 125 & 123 & 118 & 119 & 111 \\
\hline $0.70 \mathrm{~g}$ & 125 & 125 & 125 & 124 & 124 & 122 & 120 \\
\hline $0.75 \mathrm{~g}$ & 125 & 125 & 125 & 125 & 124 & 124 & 122 \\
\hline $0.80 \mathrm{~g}$ & 125 & 125 & 125 & 125 & 125 & 125 & 124 \\
\hline
\end{tabular}

The fragility curves derived from the application of far- and near-field

733 three-component seismic inputs are depicted in Figure 14. In the case of far-field

734 seismic input (see solid lines in Figure 14), the occurrence of an event with an

735 intensity of $0.50 \mathrm{~g}$ leads to probabilities of exceedance of $82 \%, 68 \%$ and $58 \%$ for the

736 Damage Limitation, Significant Damage and Near Collapse LSs, respectively. It

737 can also be noted that the fragility curves are relatively close, especially when

738 considering the last two LSs. This behavior was also evidenced when assessing the

739 seismic vulnerability of the structure subjected to uniaxial inputs. The results

740 associated with the application of near-field seismic inputs are depicted in Figure

74114 (dashed lines). In this case, the probabilities of exceeding the three LSs

742 correspond to $77 \%$, 54\% and $36 \%$ for an intensity of $0.50 \mathrm{~g}$. As for the uniaxial

743 input, there is a reduction of probability when comparing the probabilities 
associated with near- and far-field seismic inputs. The Damage Limitation and

745 Near Collapse LSs presented the lowest and highest reductions of approximately

$7465 \%$ and $22 \%$, respectively. Another comparison can be conducted considering the

747 probability of exceedance of the different LSs when applying uniaxial and three-

748 component artificial accelerograms. The probability of exceedance increased

749 between 1.9 and 2.7 times for a far-field seismic input with an intensity of $0.50 \mathrm{~g}$.

750 In the case of near-field seismic input, the application of three-component artificial 751 accelerograms with a PGA of $0.50 \mathrm{~g}$ led to an amplification of the probabilities 752 ranging between 1.84 and 3.35 times the ones obtained with uniaxial 753 accelerograms.

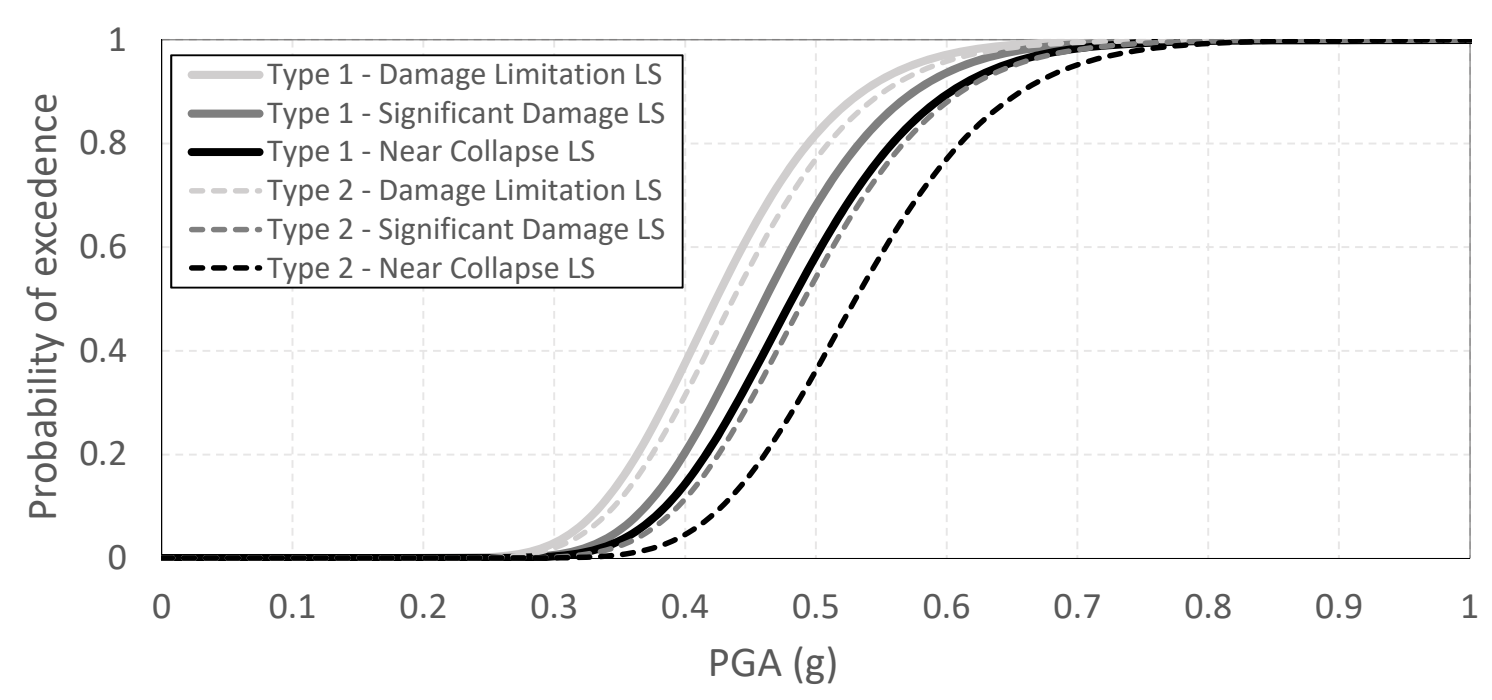

Figure 14. Analytical fragility curves derived due to the application of threecomponent artificial accelerograms.

\section{Comparison between fragility curves}

The last part of this investigation provides a comparison between fragility curves obtained by means of the proposed analytical approach and an expert-based formulation. For this purpose, the expert-based fragility functions provided by Hazus [23], for the building typology denoted as URML, is considered. URML typology corresponds to URM buildings composed by low-height bearing walls with one or two stories which somehow resemblance to the case study of this investigation. The comparison between analytical and expert-based fragility functions also required the definition of three equivalent LSs. The first LS, 
denoted as Slight Damage, is related to diagonal and stair-step cracking on masonry walls and around openings. The second one, denoted as Moderate Damage, involves the occurrence of diagonal cracking in almost all masonry wall and visible separation from diaphragms. The third LS, denoted as Extensive Damage, consists of extensive damage in most masonry walls and overturning of parapets and gable wall ends. Hazus [23] also provides a set of seismic design levels for the vulnerability assessment of different building typologies, as a function of the date of design and seismic hazard. The Low-code seismic design level was chosen for this comparison (early design codes and moderate seismicity).

This comparison involved the definition of single analytical fragility curves for the LSs selected for far- and near-field seismic inputs. For this purpose, an additional round of fitting procedures was conducted considering the total number of exceeding events as the summation of the ones obtained with uniaxial and triaxial accelerograms. The characteristics of the new analytical fragility curves, together with the expert-based ones, are reported in Table 6. Significant differences were clearly identified when comparing the characteristics of the fragility functions based on these two different formulations. The analytical mean values are significantly higher than the ones provided by expert-based formulation regardless of the corresponding equivalent LS. These differences can also be clearly noticed in Figure 15 which shows the fragility curves provided by Hazus [23] together with envelopes of far- and near-field analytical fragility curves. This figure shows that URML structures reach the different LSs when subjected to a lower intensity of seismic input when compared to the analytical envelopes. It can be observed that the occurrence of a seismic event with an intensity of $0.50 \mathrm{~g}$ leads to high probabilities of exceedance. In the case of the Slight Damage LS, this probability corresponds to 98\%, whereas for the Moderate and Extensive Damage LSs, these values are $92 \%$ and $76 \%$, respectively. This comparison demonstrates how the blind use of generic approaches to defining seismic loss of URM structures can provide unrealistic estimates. In addition, it also stresses the necessity of conducting further and more detailed investigations regarding this topic. 
Table 6. Mean value and standard deviation associated with analytical and expert-based fragility curves.

\begin{tabular}{|c|c|c|c|c|c|c|c|}
\hline \multirow[t]{2}{*}{$\begin{array}{l}\text { EC8-Part3 } \\
\text { Limit states }\end{array}$} & \multicolumn{2}{|c|}{$\begin{array}{l}\text { Far -field } \\
\text { earthquake }\end{array}$} & \multicolumn{2}{|c|}{$\begin{array}{l}\text { Near-field } \\
\text { earthquake }\end{array}$} & \multirow[t]{2}{*}{$\begin{array}{l}\text { Hazus [23] } \\
\text { Limit state }\end{array}$} & \multicolumn{2}{|c|}{$\begin{array}{l}\text { Equivalent PGA } \\
\text { Low-code seismic } \\
\text { design level }\end{array}$} \\
\hline & $\theta$ & $B$ & $\theta$ & $B$ & & $\theta$ & $\beta$ \\
\hline $\begin{array}{l}\text { Damage } \\
\text { Limitation }\end{array}$ & 0.46 & 0.23 & 0.47 & 0.24 & $\begin{array}{c}\text { Slight } \\
\text { Damage }\end{array}$ & 0.14 & 0.64 \\
\hline $\begin{array}{c}\text { Significant } \\
\text { Damage }\end{array}$ & 0.50 & 0.25 & 0.53 & 0.23 & $\begin{array}{l}\text { Moderate } \\
\text { Damage }\end{array}$ & 0.20 & 0.64 \\
\hline $\begin{array}{c}\text { Near } \\
\text { Collapse }\end{array}$ & 0.53 & 0.26 & 0.58 & 0.23 & $\begin{array}{l}\text { Extensive } \\
\text { Damage }\end{array}$ & 0.32 & 0.64 \\
\hline
\end{tabular}

793

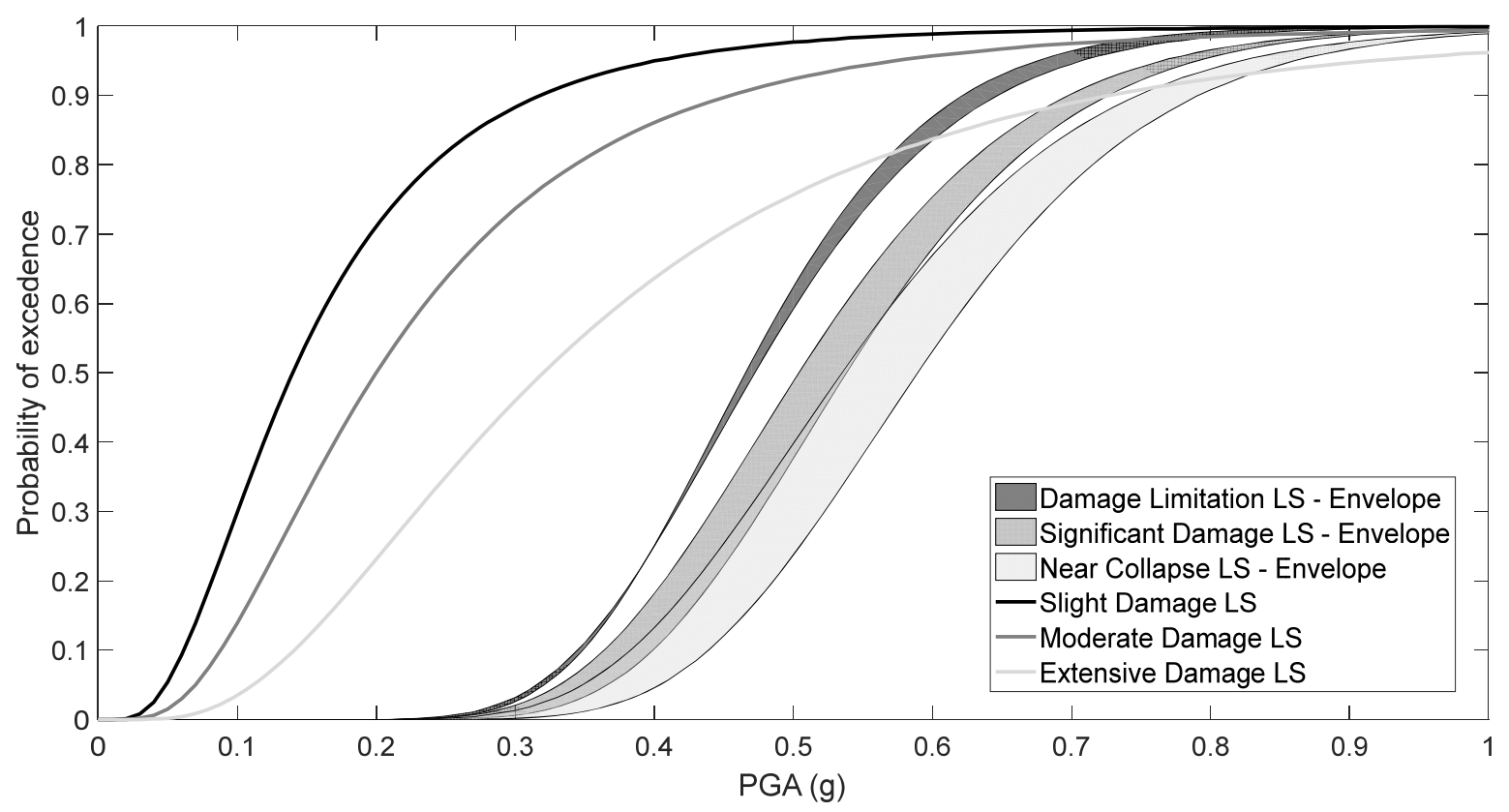

Figure 15. Comparison between analytical and expert-based fragility curves.

\section{Final considerations}

This paper presented a methodology for assessing the seismic

796 vulnerability of masonry structures characterized by predominant out-of-plane

797 failure mechanisms by means of analytical fragility curves. Such methodology

798 involves the use of an efficient DMEM approach capable of simulating in-plane and out-of-plane mechanisms with a low computational demand. In addition, the

800 proposed methodology is constituted by a series of thorough procedures associated

801 with the definition of seismic input, the definition of limit states and displacement 802 capacities, and the derivation and fitting of analytical fragility curves. Due to the 803 advantages of the adopted modelling approach, the seismic vulnerability 804 assessment involved the application of time history analyses, and it required the 
definition of suitable seismic input. In addition, the limit states have been defined following specifications provided by standards. Nevertheless, the definition of their corresponding displacement capacity was conducted by means of an alternative procedure, denoted as Capacity Dominium, based on multi-directional pushover analyses aiming at a global assessment of structural response. Finally, the derived fragility curves were subjected to a fitting process considering a maximum likelihood approach.

In the present study, this methodology has been validated by an initial application to a brick masonry structure which was experimentally and numerically investigated. The generation of the seismic input was conducted based on Type 1 and Type 2 elastic response spectra. Three LSs, namely Damage Limitation, Significant Damage and Near Collapse, were taken into consideration whose capacities were expressed in terms of horizontal top displacements of the main gable wall. These displacements were defined by means of a CD obtained by applying pushover analyses with an incremental angular step of $22.5^{\circ}$.

The seismic vulnerability assessment of the brick masonry structure involved two main sources of uncertainty. Such uncertainty was focused on the seismic input as well as the mechanical properties and geometrical properties of the structure. The artificial accelerograms were subjected to eight scaling factors between 0.45 and 0.80 , with an incremental step of 0.05 . A maximum likelihood procedure was considered for the fitting of the analytical fragility curves allowing the estimation of the probability of exceedance in accordance with the different LSs. This approach required the definition of the actual number of exceeding events which was determined by the use of the CD. Analytical fragility curves associated with the application of far and near-field seismic inputs were derived using the DME model of the brick masonry structure. These results demonstrated the capability of the proposed modeling approach for performing sophisticated analyses for practical applications.

In particular, for the analyzed structure, an important difference was found between uniaxial and triaxial seismic input: on average, considering all Limit States and a probability of exceedance of $50 \%$, a $19 \%$ reduction of the PGA input is found when comparing the triaxial and the uniaxial seismic inputs. 
837 Additionally, the comparison between analytical and expert-based formulations

838 showed some marked differences in terms of fragility curves and their

839 corresponding probabilities of exceedance. Therefore, it is necessary to carefully

840 apply expert-based formulations for a specific location and structural typology, 841 and further investigations associated with the seismic vulnerability of URM

842 structures are required. The definition of a more rigorous procedure for the

843 estimation of the displacement capacity, suitable in a dynamic context and that 844 involves in-plane and out-of-plane mechanisms, constitutes an important task 845 that needs to be investigated in future.

846 In general, it is important to notice that the main steps in this 847 methodology, namely, application of multidirectional pushover analyses for the 848 definition of the displacement capacity as well as nonlinear dynamic analyses for

849 the derivation of fragility curves, require a reasonable computational burden. The 850 analysis demand required for this type of assessment may constitute an important 851 limitation of this methodology; however, it is significantly low when compared to 852 sophisticated and refined FE numerical models characterized by a large number 853 of DOFs. As previously stated, the application of a single nonlinear dynamic 854 analysis was characterized by an average duration of 30 minutes. For this reason, 855 the authors believe that the proposed methodology may allow a thorough assessment of the seismic vulnerability of URM structures.

\section{7. Acknowledgment}

The first author gratefully acknowledges the financial support of the Peruvian Institution Innovate Perú/FINCyT (Fondo para la Innovación, Ciencia y

860 Tecnología) through the $\mathrm{PhD}$ grant BECA-1-P-078-13. The first author 861 acknowledge the support and helpful advices provided by Dr. Helder Sousa from 862 the University of Minho.

\section{References}

864 [1] P. G. Asteris, A. Moropoulou, A. D. Skentou, M. Apostolopoulou, A. Mohebkhah, L. 865 Cavaleri, H. Rodrigues, and H. Varum, "Stochastic Vulnerability Assessment of 
Masonry Structures: Concepts, Modeling and Restoration Aspects," Applied Sciences, vol. 9, p. 243, (2019).

[2] B. R. Ellingwood, "Earthquake risk assessment of building structures," Reliability Engineering \& System Safety, vol. 74, pp. 251-62, (2001).

[3] T. Rossetto and A. Elnashai, "Derivation of vulnerability functions for Europeantype RC structures based on observational data," Engineering Structures, vol. 25, pp. 1241-63, (2003). doi: 10.1016/S0141-0296(03)00060-9

[4] ATC-13, Earthquake damage evaluation data for California, Applied technology council FEMA contract no. EMW-C-0912, 1985.

[5] M. Rota, A. Penna, and C. L. Strobbia, "Processing Italian damage data to derive typological fragility curves," Soil Dynamics and Earthquake Engineering, vol. 28, pp. 933-947, (2008).

[6] M. Rota, "Advances in the derivation of fragility curves for masonry buildings," $\mathrm{PhD}$ thesis, European School for Advanced Studies in Reduction of Seismic Risk (ROSE School), Pavia, Italy, (2007).

[7] ATC, FEMA-273: NEHRP Guidelines for the seismic rehabilitation of buildings. Basic procedures manual, Applied Technology Council (ATC), 1997.

[8] ATC, FEMA-306: Evaluation of earthquake damaged concrete and masonry wall buildings. Basic Procedures Manual, Applied Technology Council (ATC), 1998.

[9] Eurocode 8: Design of structures for earthquake resistance - Part 3: General rules, seismic actions and rules for buildings, Design Code EN 1998-3, 2005.

[10] NZSEE: Assessment and improvement of the structural performance of buildings in earthquakes. New Zealand Society of Earthquake Engineering., University of Auckland, 2006.

[11] NTC 2008, Decreto Ministeriale 14/1/2008: Norme tecniche per le costruzioni., Ministry of Infrastructures and Transportations, 2008.

[12] G. M. Calvi, "A displacement-based approach for vulnerability evaluation of classes of buildings," Journal of Earthquake Engineering, vol. 3, pp. 411-38, (1999).

[13] A. J. Kappos, G. Panagopoulos, C. Panagiotopoulos, and G. Penelis, "A hybrid method for the vulnerability assessment of R/C and URM buildings.," Bulletin of Earthquake Engineering, vol. 4, pp. 421-44, (2006).

[14] P. G. Asteris, "On the structural analysis and seismic protection of historical masonry structures," The Open Construction and Building Technology Journal, vol. 2, pp. 124-33, (2008).

[15] A. Mouyiannou, M. Rota, A. Penna, and G. Magenes, "Identification of suitable limit states for nonlinear dynamic analyses of masonry structures," Journal of Earthquake Engineering, vol. 18, pp. 231-63, (2014).

[16] S. Petry and K. Beyer, "Influence of boundary conditions and size effect on the drift capacity of URM walls," Engineering Structures, vol. 65, pp. 76-88, (2014).

[17] S. Lagomarsino and S. Cattari, "Seismic performance of historical masonry structures through pushover and nonlinear dynamic analyses," in Perspectives on European Earthquake Engineering and Seismology, Springer, (2015), pp. 265-292.

[18] S. Lagomarsino and S. Cattari, "PERPETUATE guidelines for seismic performance-based assessment of cultural heritage masonry structures," Bulletin of Earthquake Engineering, vol. 13, pp. 13-47, (2015). doi: 10.1007/s10518-0149674-1

[19] M. Rota, A. Penna, and G. Magenes, "A methodology for deriving analytical fragility curves for masonry buildings based on stochastic nonlinear analyses," Engineering Structures, vol. 32, pp. 1312-23, (2010).

[20] G. Grünthal, "European macroseismic scale 1998 (EMS 1998). Council of Europe, Cahiers du Centre Europe'en de Géodynamique et de Sismologie," p. 15. 
[21] B. Omidvar, B. Gatmiri, and S. Derakhshan, "Experimental vulnerability curves for the residential buildings of Iran," Natural Hazards, vol. 60, pp. 345-365, (2012). doi: 10.1007/s11069-011-0019-y

[22] J. Park, P. Towashiraporn, J. I. Craig, and B. J. Goodno, "Seismic fragility analysis of low-rise unreinforced masonry structures," Engineering Structures, vol. 2009, pp. 125-37, (2009).

[23] HAZUS 99 earthquake loss estimation methodology, technical manual, N.-N. I. o. B. Science, 1999.

[24] L. Pasticier, C. Amadio, and M. Fragiacomo, "Non-linear seismic analysis and vulnerability evaluation of a masonry building by means of the SAP2000 V.10 code," Earthquake Engineering \& Structural Dynamics, vol. 37, pp. 467-485, (2008).

[25] CSI (Computers and Structures Inc.), "SAP2000 v10 Integrated Finite Element Analysis and Design of Structures," (2004), Berkeley,

[26] P. G. Asteris, M. G. Douvika, M. Apostolopoulou, and A. Moropoulou, "Seismic and Restoration Assessment of Monumental Masonry Structures," Materials, vol. 10, p. 895, (2017).

[27] M. Apostolopoulou, E. Aggelakopoulou, L. Siouta, A. Bakolas, M. G. Douvika, P. G. Asteris, and A. Moropoulou, "A methodological approach for the selection of compatible and performable restoration mortars in seismic hazard areas," Construction and Building Materials, vol. 155, pp. 1-14, (2017).

[28] P. G. Asteris, M. P. Chronopoulos, C. Z. Chrysostomou, H. Varum, V. Plevris, N. Kyriakides, and V. Silva, "Seismic vulnerability assessment of historical masonry structural systems," Engineering Structures, vol. 62-63, pp. 118-134, (2014).

[29] S. Lagomarsino, A. Penna, A. Galasco, and S. Cattari, "TREMURI program: An equivalent frame model for the nonlinear seismic analysis of masonry buildings," Engineering Structures, vol. 56, pp. 1787-1799, (2013).

[30] M. A. Erberik, "Generation of fragility curves for Turkish masonry buildings considering in-plane failure modes," Earthquake Engineering \& Structural Dynamics, vol. 37, pp. 387-405, (2008).

[31] Y. Mengi, H. D. McNiven, and A. D. Tanrıkulu, "Models for nonlinear earthquake analysis of brick masonry buildings.," University of California at Berkeley(1992).

[32] D. D'Ayala, "Force and displacement based vulnerability assessment for traditional buildings," Bulletin of Earthquake Engineering vol. 3, pp. 235-65, (2005).

[33] S. Cattari, S. Frumento, S. Lagomarsino, S. Parodi, and S. Resemini, "Multi-level procedure for the seismic vulnerability assessment of masonry buildings: The case of Sanremo (north-western italy)," in 1st European Conference on Earthquake Engineering and Seismology (ECEES), Geneva, Switzerland (2006).

[34] G. Milani and G. Venturini, "Automatic fragility curve evaluation of masonry churches accounting for partial collapses by means of 3D FE homogenized limit analysis," Computers and Structures, vol. 89, pp. 1628-1648, (2011).

[35] I. Caliò, M. Marletta, and B. Pantò, "A new discrete element model for the evaluation of the seismic behaviour of unreinforced masonry buildings," Engineering Structures, vol. 40, pp. 237-338, (2012).

[36] B. Pantò, F. Cannizzaro, I. Caliò, and P. B. Lourenço, "Numerical and experimental validation of a 3D macro-model for the in-plane and out-of-plane behaviour of unreinforced masonry walls," International Journal of Architectural Heritage, (2017). doi: 10.1080/15583058.2017.1325539

[37] T. Takeda, M. A. Sozen, and N. N. Nielsen, "Reinforced concrete response to simulated earthquakes," Journal of the Structural Division, vol. 96, pp. 2557-2573, (1970). 
[38] V. Turnsek and F. Cacovic, "Some experimental result on the strength of brick masonry walls," in 2nd International Brick Masonry Conference, Stoke-on-Trent, UK (1971).

[39] C. Chácara, F. Cannizzaro, B. Pantò, I. Caliò, and P. B. Lourenço, "Assessment of the Dynamic Response of Unreinforced Masonry Structures using a MacroElement Modelling Approach," Earthquake Engineering and Structural Dynamics, vol. 47, pp. 2426-46, (2018).

[40] HISTRA s.r.l, "HiStrA (Historical Structure Analysis) Release 17.2.3," ed. Catania, Italy, $(2015$.

[41] F. Cannizzaro, B. Pantò, M. Lepidi, S. Caddemi, and I. Caliò, "Multi-directional seismic assessment of historical masonry buildings by means of macro-element model-ling: Application to a building damaged during the L'Aquila earthquake (Italy)," Buildings, vol. 7, (2017).

[42] J. W. Baker, "Efficient Analytical Fragility Function Fitting Using Dynamic Structural Analysis," Earthquake Spectra, vol. 31, pp. 579-99, (2015).

[43] P. X. Candeias, A. Campos Costa, N. Mendes, A. A. Costa, and P. B. Lourenço, "Experimental Assessment of the Out-of-Plane Performance of Masonry Buildings Through Shaking Table Tests," International Journal of Architectural Heritage, vol. 11, pp. 31-58, (2017).

[44] TNO, "DIANA - DIsplacement method ANAlyser," (2018), Delft, Netherlands,

[45] Eurocode 8: Design of structures for earthquake resistance - Part 1: General rules, seismic actions and rules for buildings, EN 1998-1, 2004.

[46] NP EN 196-8, Eurocode 8: Design of structures for earthquake resistance Part 1: General rules, seismic actions and rules for buildings-Portuguese Institute for Quality, 2010.

[47] D. A. Gasparini and E. H. Vanmarcke, "SIMQKE, A Program for Artificial Motion Generation: User's Manual and Documentation," (1976), Department of Civil Engineering, MIT, USA,

[48] L. Mendes, "LNEC-SPA: Signal Processing and Analysis Tools for Civil Engineers," Lisbon, Portugal Patent, 2008.

[49] B. Pantò, F. Cannizzaro, S. Caddemi, I. Caliò, C. Chácara, and P. B. Lourenço, "Nonlinear Modelling of Curved Masonry Structures after Seismic Retrofit through FRP Reinforcing," Buildings, vol. 7, p. 79, (2017). doi: 10.3390/buildings7030079

[50] P. B. Lourenço, "Recent advances in masonry modelling : Micromodelling and homogenisation," in Multiscale modeling in solid mechanics: Computational approaches, U. Galvanetto and M. H. Ferri Aliabadi, London, UK, (2009.

[51] JCSS Probability Model Code Part 3: Resistance Models, Joint Committee of Structural Safety, 2011.

[52] C. Chácara, P. B. Lourenço, B. Pantò, F. Cannizzaro, and I. Caliò, "Macro-Element Mass Matrix for the Dynamic Assessment of Unreinforced Masonry Structures," in Congreso de Métodos Numéricos en Ingeniería, Valencia, Spain (2017). 